\title{
Performance of radial fuel shuffling sodium cooled Breed and Burn reactor core
}

\author{
M. Y. Zheng, W. X. Tian, D. L. Zhang, S. Z. Qiu, G. H. Su* \\ State Key Laboratory of Multiphase Flow in Power Engineering, School of \\ Nuclear Science and Technology, Xi'an Jiaotong University, Xi'an 710049, China \\ *Corresponding author. Tel \& Fax: +86-29-82663401 \\ Email: ghsu@mail.xjtu.edu.cn
}

\begin{abstract}
In this paper, performance of radial fuel shuffling of sodium cooled breed and burn reactor core is investigated. Neutronics and depletion calculations are carried out by MCORE based on the ENDF/B-VII data library. Thermal-hydraulic analysis is performed based on a self-developed parallel channels model steady-state code SAST. First of all, the assembly parameters are optimized from neutronics and thermalhydraulics. The results show that assembly with 127 fuel rods and P/D of 1.12 is the best design. Secondly, the core critical features and radial power peaking factors of the inward and outward fuel shuffling strategy under different fuel shuffling periods are carried out. The results show that keff of the beginning of equilibrium cycle (BOEC) and end of equilibrium cycle (EOEC) of both the inward and outward fuel shuffling strategy parabolically vary with the fuel shuffling period. Power peaking factor of the inward fuel shuffling strategy decreases with the increase of fuel shuffling period exponentially, while that of the outward fuel shuffling strategy increases with the fuel shuffling period exponentially. The outward fuel shuffling strategy with shuffling period of 500 days performs better in core critical features and radial power peaking
\end{abstract}


factors. Reactivity coefficients of the optimized core are calculated. Finally, preliminary thermal-hydraulic analysis of the optimized core is performed. The results show that maximum cladding interface temperature and maximum fuel temperature are all within the acceptable limits.

Key words: Breed and Burn reactor, Assembly optimization, Fuel shuffling strategy, Core performance

\section{Introduction}

Light Water Reactors (LWRs) utilize about only $0.6 \%$ of the overall uranium. For the once-through Fast Breeder Reactors (FBRs), the uranium utilization is not significantly different from the LWRs due to the high uranium enrichment required to fuel the FBRs (Greenspan et al., 2011). Closed fuel cycle can make high uranium utilization, but fuel reprocessing is difficult and expensive. Fortunately, Breed and Burn reactors can obtain a very high level of burn-up using non-enriched uranium, realize significantly high uranium utilization and do not need fuel reprocessing.

Feinberg (1958) firstly proposed the concept of Breed and Burn reactor, in which burning wave propagates continuously through the fertile fuel region. During the past five decades of investigation, two concepts of Breed and Burn reactors have been proposed: Traveling Wave Reactor (TWR) and Standing Wave Reactor (SWR). In TWR, the breeding/burning wave moves through the fuel, while fuel is shuffled in or out of the burning region in SWR. The TWR concept was firstly investigated by Feoktistov (1988), finding that traveling nuclear burning wave can self-sustained in the Breed and 
Burn reactors. After that, a series of studies for TWR were performed by Teller et al. (1996), Seifritz (2000), Sekimoto et al. (2001), Van Dam (2003), Fomin et al. (2008), Chen et al. (2008, 2012), and so on. The first SWR core design was conducted at Brookhaven National Laboratory (BNL) in collaboration with the Massachusetts Institute of Technology (MIT) in 1970s. After that, the studies of SWR were performed by Marshall et al. (2005), Greenspan et al. (2009), Chen et al. (2011), Heidet et al. (2012, 2013), Qvist et al. (2012), Zhang et al. (2013), Zheng et al. (2014a, 2014b, 2015), and so on. In 2008, the Terra Power LLC was founded to develop commercial TWR (actually SWR), which brings a huge boost to the investigation of Breed and Burn reactors.

In the previous studies of SWR type of Breed and Burn reactor, the fuel shuffling strategy and thermal-hydraulic analysis have been investigated by some researchers. Chen et al. (2011) compared the inward and outward fuel drifting theoretically and found that the inward fuel drifting has a better breeding utilization than the outward one, in which the achieved asymptotic $k_{\text {eff }}$ is lower. Zhang et al. (2013) studied the power peaking factor, asympototic $k_{\text {eff }}$ and burn-up of different shuffling period based on the European Sodium cooled Fast Reactor (ESFR). Zheng et al. (2014a, 2014b, 2015) proposed the concept of checkerboard type Breed and Burn reactor, in which a number of breeding assemblies are arranged in the center core to increase the breeding ability. Qvist et al. (2014) developed an automated fast reactor core design code ADOPT, which has been applied to Breed and Burn reactor. Heidet et al. (2013) performed a 
preliminary neutronics design of a Breed and Burn reactor core, in which an improved shuffling scheme was proposed and preliminary thermal-hydraulic analysis was performed. However, the core was modeled as concentric cylindrical regions, which limits the engineering practicability of the research results.

The objective of the present paper is to optimize the assembly parameters from neutronics and thermal-hydraulics, compare the core critical features and power peaking factors of the inward and outward fuel shuffling strategy under different fuel shuffling periods, and perform preliminary thermal-hydraulic analysis of the optimized core. The assembly parameters optimization is performed in Section 2. A detailed description of the Breed and Burn reactor core, inward and outward fuel shuffling strategy, and the core modeling are provided in Section 3. Section 4 compares the assembly performance from neutronics and thermal-hydraulic, the core critical features and power peaking factor under different fuel shuffling period and performs preliminary thermal-hydraulic analysis of the optimized core. The general conclusions of the present paper are provided in Section 5.

\section{Assembly Design}

\subsection{Assembly description}

Assembly parameters will influence the loading of uranium, the neutron spectrum, and then influence the breeding ability of assembly. At the same time, assembly parameters will influence the thermal-hydraulic parameters, such as coolant flow area and hydrodynamic diameter, and then influence the thermal-hydraulic characteristics. 
So, the assembly parameters should be optimized to satisfy neutronics and thermalhydraulic limits. The main purpose of assembly optimization is to increase the assembly breeding ability and decrease the maximum cladding interface temperature, maximum fuel temperature and pressure drop by adjusting the P/D (Pitch/Diameter) parameters and the number of fuel rods per assembly through keeping the main assembly parameters unchanged, such as inside flat-to-flat distance, assembly pitch and active core height.

The main parameters of assembly are listed in Table 1. As shown in Fig. 1 that 91, 127, 169, 217 and 271 fuel rods assembly, commonly used in FBRs, are taken into account. P/D of $1.04,1.06,1.08,1.10,1.12,1.14,1.16,1.18$ and 1.20 are taken into account. Detailed assembly parameters for different fuel rods with different P/D are listed in Table 2 to Table 6 . Metallic fuel $\mathrm{U}+10 \% \mathrm{Zr}$ is used as fuel material; the fuel nominal density is $16.0 \mathrm{~g} / \mathrm{cm}^{3}$ and the smear factor is $75 \%$. Sodium is used as coolant with a density of $0.85 \mathrm{~g} / \mathrm{cm}^{3}$. Ferritic/Martensitic alloy HT-9 is used as the cladding material with a density of $7.9 \mathrm{~g} / \mathrm{cm}^{3}$.

\subsection{Assembly simulation}

MCORE, which couples MCNP and ORIGEN, is used to perform neutronics and depletion calculations in the present paper (Zheng et al., 2014c). MCORE has been verified by VVER-1000 LEU assembly benchmark and OECD/NEA fast reactor benchmark. The NJOY code was previously used to generate the cross-section data, used by MCNP, based on the original ENDF/B-VII libraries. The displacements per 
atom (DPA) of structural material can not be calculated by MCORE, so DPA of cladding material is not considered in the present paper.

For the thermal-hydraulic analysis, a steady-state code SAST has been developed based on parallel channels model. The calculation procedure of SAST is shown in Fig. 2. SAST has been verified by KALIMER-600 equilibrium design value, the results obtained by SAST show a good agreement with the design value. Deviations from design value is found to be $-2.58 \%$ and $-0.52 \%$ for assembly flow rate and coolant outlet temperature.

\section{Core design and fuel shuffling strategy}

\subsection{Core description}

Previous research at Xi'an Jiaotong University proposed the concept of sodium cooled checkerboard type Breed and Burn reactor (Zheng et al., 2014 a, b) and performed MA transmutation analysis based on this concept (Zheng et al., 2015). The so-called checkerboard type means that a number of breeding assemblies are arranged in the inner core in a scattered way to increase the breeding ability of the core. As mentioned by Greenspan et al. (2011) that fuel discharged from a Breed and Burn reactor can be additionally used in Breed and Burn reactor as ignition material, spent fuel assemblies are discharged from the core other than moved to the outer core. The present design is named as BSWR (checkerboard type Standing Wave Reactor), set as core design A in the present paper. For the BSWR, if outward fuel shuffling strategy is adopted, fully bred assemblies will be moved to the center of the inner core, which will 
increase the power density of this area and bring a big radial power peaking factor. Based on previous research experience, breeding assemblies in the inner core are not included in the present paper, while the outer core and the arrangement of control rod assemblies, absorbing assemblies, reflector assemblies and shield assemblies are the same, set as core design B in the present paper.

As mentioned above that $\mathrm{U}+10 \% \mathrm{Zr}$, HT-9, sodium and $\mathrm{B}_{4} \mathrm{C}$ are used as fuel material, structural material, coolant and absorbing material, respectively. The active core is divided into two regions in radial direction, the inner core and the outer core. 204 depleted uranium assemblies are loading in the outer core and 48 absorbing assemblies are arranged in the outer core to absorb neutrons and reduce power density in this area. About three layers 252 reflector assemblies are arranged in the outside of the outer core and about two layers 198 shield assemblies are arranged in the outer most of the core. For core design A, $14.0 \%$ and $11.0 \%$ enrichment ignition assemblies are arranged in the inner core with the number of 96 and 60, respectively. 36 depleted uranium assemblies are loaded in the inner core in a checkerboard type way. The core layout in radial view is shown in Fig. 3. For core design B, 5.0\%, 9.0\%, 11.0\%, 14.0\%, $12.0 \%$ and $10.0 \%$ enrichment ignition assemblies are arranged in the inner core with the number of $12,18,36,30,36$ and 60 , respectively. The core layout in radial view is shown in Fig. 4. The loading of ${ }^{235} \mathrm{U}$ is the same for the two cores. Core and surrounding layout in section view and detailed core parameters for the two cores are shown in Fig. 5 and Table 7 , respectively. 


\subsection{Fuel shuffling strategy}

Two kinds of fuel shuffling strategy are modeled in the present paper, the inward fuel shuffling strategy (for core design A) and the outward fuel shuffling strategy (for core design B), which are shown in Fig. 6. The 396 ignition and breeding assemblies are divided into 66 groups, so every group consists of 6 assemblies. The distance of assemblies of the same group to the center is almost the same.

The diagram of the inward fuel shuffling strategy is shown in Fig. 6 (a). Fresh fuel assemblies are charged from the outer side of the outer core and spent fuel assemblies are discharged from the inner side of the inner core. Assemblies of the same group are moved to the next group inwards, except breeding assemblies in the inner core. Breeding assemblies in the inner side of the outer core are moved to breeding assembly position of the inner core, moved outwards, and then moved to the outer side of the inner core.

The diagram of the outward fuel shuffling strategy is shown in Fig. 6 (b). Fresh fuel assemblies are charged from the outer side of the outer core and spent fuel assemblies are discharged from the outer side of the inner core. Assemblies in the outer core of the same group are moved to the next group inwards, while assemblies in the inner core are moved outwards. Breeding assemblies in the inner side of the outer core are moved to center of the inner core.

To make good use of the ignition assemblies in the inner core and ensure enough breeding in the breeding assemblies in the inner core and inner side of the outer core, 
the ignition assemblies are not moved during the first 3 fuel shuffling steps.

\subsection{Reactor core simulation}

The depletion analysis is performed for every fuel assembly of the 1/6 core in the present paper, as shown in Fig. 7. Fuel shuffling period of 300, 400, 500, 600, 700, 800, 900, 1000, 1100, 1200 and 1300 days are modeled. The active core is divided into ten blocks in axial direction. The control and safety rod (CR\&SR) are assumed to be withdrawn from the core, which means the CR\&SR are filled with sodium. Heidet et al. (2013) performed the comparison of the multiplication factor between a cylindrical core model and an assembly-level core model, and observed that the error between the two models are within $0.4 \%$. In the present paper, a more sophisticated homogenous assembly-level core model is used. Four thousands neutron histories per cycle and 150 active cycles are used to obtain $k_{\text {eff }}$ with a fractional statistical error of less than 100 pcm. As mentioned before, DPA of cladding material is not considered during core depletion calculation in the present paper.

For core thermal-hydraulic, constraints accounted for are as follows: maximum cladding interface temperature, maximum fuel temperature and core pressure drop are $650^{\circ} \mathrm{C}, 1240^{\circ} \mathrm{C}$ and $1.0 \mathrm{MPa}$, respectively. To reduce the difference of outlet coolant temperature, cladding interface temperature and fuel temperature, assemblies of almost the same power are set as a group and the flow rate of every group is adjusted by grid plate based on the power density, which indicates that the inlet local resistance coefficient of assemblies of the same group are identical. Assembly numeration of the 
$1 / 6$ core for thermal hydraulic simulation is shown in subsequent section.

\section{Results and discussions}

\subsection{Assembly optimization}

Neutron balance analysis and thermal-hydraulic analysis of a breeding assembly are performed to find the optimal P/D and the number of fuel rods per assembly. The core is assumed to operate at a radial power peaking factor of 3.2 based on previous research experience. The assembly flow rate is obtained based on its power and the pressure drop includes the whole length of the assembly. The thermal power, flow rate, inlet temperature and inlet pressure are $1250 \mathrm{MWt}, 8000.0 \mathrm{~kg} / \mathrm{s}$ (with by-pass flow of $8.0 \%), 360.0^{\circ} \mathrm{C}$ and $1.5 \mathrm{MPa}$, respectively.

Neutron balance is performed based on the relation deduced by Greenspan et al. (2011). The minimum required burn-up is that $B U$ for which:

$$
N_{H M} \int \bar{v}(B U)\left[1-1 / k_{\infty}(B U)\right] d(B U)=0
$$

where, $N_{H M}$ is the Heavy Metal (HM) atom density, $\bar{v}(B U)$ is the average number of neutrons emitted per fission, $B U$ is expressed in Fissions per Initial heavy Metal Atom (FIMA). In the present paper, a unit assembly neutron balance is performed, so the neutron losses are not accounted for.

The $k_{\infty}$ evolution with burn-up is calculated for a unit assembly used as breeding assembly (depleted uranium) in Breed and Burn reactor core. The $k_{\infty}$ evaluation of different P/D assemblies is shown in Fig. 8 and the corresponding neutron balance as a function of burn-up is shown in Fig. 9. It can be found in Fig. 8 that the multiplication 
factor and the multiplication factor satisfy critical criteria decreases with the increase of $\mathrm{P} / \mathrm{D}$, which determines the fuel volume fraction, due to the decrease of fuel volume fraction. The minimum required burn-up is the burn-up at which the net number of excess neutrons is zero. It can be noted from Fig. 9 that the minimum required burn-up increases with P/D. From the neutron balance analysis, it can be found that the uranium utilization ability decreases with the increase of P/D.

Thermal-hydraulic performance of different fuel rods assemblies with different $\mathrm{P} / \mathrm{D}$ is modeled. Maximum cladding interface temperature as a function of fuel rod number and P/D is shown in Fig. 10. It can be concluded that maximum cladding interface temperature increases with the number of fuel rod with constant P/D due to the increase of linear power density, and increases with P/D with constant number of fuel rod due to the increase of volumetric heat release rate. For all the fuel rod number and P/D design, the cladding interface temperatures are within the design limit and have a large safety margin. Maximum fuel temperature as a function of fuel rod number and P/D is shown in Fig. 11. It can be found that the maximum fuel temperature increases with the number of fuel rod and P/D for the same reason of the cladding interface temperature, and the maximum fuel temperature for 91 fuel rods assembly is too close to design limit $800{ }^{\circ} \mathrm{C}$. The pressure drop as a function of fuel rods number and P/D is shown in Fig. 12. It can be found that the pressure drop through the whole assembly increases with the number of fuel rod with constant P/D due to the decrease of hydraulic diameter, and decreases with the increase of P/D with constant number of fuel rod due 
to the increase of coolant area. For P/D less than 1.10, the pressure drop dissatisfies the design limit 1.0 MPa. It is important to note at the same time that the inlet partial pressure drop is not considered during assembly thermal-hydraulic analysis. To comprehensively consider the neutron balance and thermal-hydraulic analysis, assembly with 127 fuel rods and P/D of 1.12 is the optimal design, which will be used in the core analysis below. The maximum cladding interface temperature, maximum fuel temperature and pressure drop have a safety margin of $126.36^{\circ} \mathrm{C}, 119.2^{\circ} \mathrm{C}$ and $0.08 \mathrm{MPa}$, respectively.

\subsection{Core critical feature}

Core critical features of the inward and outward fuel shuffling strategy during operation are compared as fuel shuffling period of 500 days for example, shown in Fig. 13. It can be concluded from this figure that $k_{\text {eff }}$ increases fast during the first three fuel cycles due to the breeding assemblies in the inner core or in the inner side of the outer core, decreases rapidly with the discharging of high enrichment ignition assemblies, and then reaches asymptotic equilibrium cycle slowly after about 30 fuel shuffling steps due to breeding. As 36 breeding assemblies are arranged in the inner core, $k_{\text {eff }}$ of the inward fuel shuffling strategy increases faster than that of the outward one during the first three fuel shuffling steps. As none enough bred breeding assemblies are moved to the center of the inner core and high enrichment ignition assemblies are discharged from the outer side of the inner core, $k_{\text {eff }}$ of the outward fuel shuffling decreases faster than that of the inward one after the first three fuel shuffling steps. 
$k_{\text {eff }}$ of equilibrium cycle of different fuel shuffling periods are shown in Fig. 14. It can be found that $k_{\text {eff }}$ of both the beginning of equilibrium cycle (BOEC) and end of equilibrium cycle (EOEC) parabolically vary with the fuel shuffling period. When fuel shuffling period is short, $k_{\text {eff }}$ of the EOEC is greater than that of the BOEC due to the breeding of fuel. While the difference of $k_{e f f}$ between EOEC and BOEC decreases slowly with the increase of fuel shuffling period due to the accumulation of fission products and consumption of fissile nuclides. It can also be found that the core critical feature of the outward fuel shuffling is better than that of the inward one when fuel shuffling period is long.

As shown in Fig. 13 that $k_{\text {eff }}$ varies with core operation. $k_{\text {eff }}$ of the equilibrium cycle is not the only factor that determines the critical feature of the core. Minimum $k_{\text {eff }}$ during the whole life, as shown in Fig. 15, is another important factor that determines the critical feature of the core during operation. It can be found that minimum $k_{\text {eff }}$ during the whole life parabolically vary with the fuel shuffling period. Minimum $k_{\text {eff }}$ of the inward fuel shuffling strategy during the whole life is greater than that of the outward one when fuel shuffling period is short and the trend reverses when fuel shuffling period is greater than 600 days. It can be concluded from Fig. 14 and Fig. 15 that fuel shuffling period 500, 600, 700, 800, 900 and 1000 days satisfy the critical criteria for the inward fuel shuffling strategy, and fuel shuffling period 500, 600, 700, $800,900,1000,1100$ and 1200 days satisfy the critical criteria for the outward fuel shuffling strategy. 


\subsection{Power distribution and burn-up feature}

Radial power peaking factor is shown in Fig. 16. Results show that radial power peaking factor of the inward fuel shuffling strategy decreases with the fuel shuffling period exponentially. When fuel shuffling period is short, BOEC radial power peaking factor of the inward fuel shuffling is smaller than that of the EOEC, and the trend reverses when the fuel shuffling period is greater than 700 days. Radial power peaking factor of the outward fuel shuffling strategy increases with the fuel shuffling period exponentially. It is quite different from the inward fuel shuffling strategy that when the fuel shuffling period is short, BOEC radial power peaking factor of the outward fuel shuffling is greater than that of the EOEC, and the trend reverses when the fuel shuffling period is greater than 400 days. It can also be found from this figure that radial power peaking factor of the inward fuel shuffling is less than 3.2 when the fuel shuffling period is greater than 500 days, while that of the outward fuel shuffling is less than 3.2 when the fuel shuffling period is less than 700 days.

Power distribution of the inward fuel shuffling strategy as a function of fuel shuffling period for which satisfies critical criteria and radial power peaking factor criteria is shown in Fig. 17. It can be found that power in the inner core decreases with the fuel shuffling period, while power in the outer core increases with the fuel shuffling period. It can also be found that the power distribution of the equilibrium cycle is quite different from the beginning of life (BOL) for the inward fuel shuffling strategy. Power distribution of the outward fuel shuffling strategy as a function of fuel shuffling period 
for which satisfies critical criteria and radial power peaking factor criteria is shown in

Fig. 18. It can be found that power in the inner core increases with the fuel shuffling period, while power in the outer core decreases with the fuel shuffling period. It can be found from Fig. 17 and Fig. 18 that the difference of power distribution between equilibrium cycle and BOL of the outward fuel shuffling strategy is less than that of the inward one. In comparison, fuel shuffling period of 600 days and 500 days are better for inward and outward fuel shuffling strategy, and the power distribution of BOL, BOEC and EOEC are shown in Fig. 19 and Fig. 20, respectively. It can be found that the difference of power distribution for the outward fuel shuffling strategy is obvious smaller than that of the inward one. The outward fuel shuffling core with fuel shuffling period of 500 days is the optimized design.

The average discharged burn-up is shown in Fig. 21. It can be found that the average discharged burn-up increases linearly with the fuel shuffling period and average discharged burn-up of the outward fuel shuffling is a little bigger than that of the inward one, which is due to the difference of power distribution and loading of uranium.

\subsection{Thermal-hydraulic analysis}

Preliminary thermal-hydraulic analysis of the equilibrium cycle is performed for the outward fuel shuffling core with fuel shuffling period of 500 days. The core parameters are as described in section 3.1.

As radial power peaking factor of the EOEC is greater than that of the BOL and 
BOEC for the outward fuel shuffling strategy core with fuel shuffling period of 500 days, EOEC power distribution is used to perform flow grouping, as shown in Fig. 22. The core is divided into 18 flow groups. Relative power flow ratio for BOL, BOEC and EOEC is shown in Fig. 23. It can be found that, relative power flow ratio of EOEC is close to unit, that of BOEC for the inner side of the inner core is a little less than unit and a little bigger than unit for the outer side of the inner core, that of BOL for the middle of the inner core is obvious bigger than unit. Based on the power distribution, hot channels of BOL, BOEC and EOEC are assembly No. 14, 13 and 9, respectively. Temperature distribution of hot channels are shown in Fig. 24. It can be found that, maximum cladding interface temperature of BOL, BOEC and EOEC are $567.6^{\circ} \mathrm{C}$, $524.9^{\circ} \mathrm{C}$ and $523.0^{\circ} \mathrm{C}$, which are all within the design limit and have a safety margin of $82.4^{\circ} \mathrm{C}, 125.1^{\circ} \mathrm{C}$ and $127.0^{\circ} \mathrm{C}$, respectively. Maximum fuel temperature of BOL, BOEC and EOEC are $632.2^{\circ} \mathrm{C}, 599.6^{\circ} \mathrm{C}$ and $599.9^{\circ} \mathrm{C}$, which are all within the design limit and have a safety margin of $167.8^{\circ} \mathrm{C}, 200.4^{\circ} \mathrm{C}$ and $200.1^{\circ} \mathrm{C}$, respectively.

From the core critical feature and radial power distribution, it can be found that the outward fuel shuffling core with fuel shuffling period of 500 days are the optimized design, and the average discharged burn-up is $27.8 \%$. At the same time, maximum cladding interface temperature and maximum fuel temperature are within the design limits. Main parameters of the outward fuel shuffling core with fuel shuffling period of 500 days are listed in Table 8.

\section{Conclusions}


In this paper, assembly parameters have been optimized from neutronics and thermal-hydraulics for a sodium cooled Breed and Burn reactor core. Core critical features and power peaking factors of the inward and outward fuel shuffling strategy under different fuel shuffling periods have been performed. Preliminary thermalhydraulic analysis of the core has been performed finally. Assembly optimization results show that: (1) the uranium utilization ability increase with $\mathrm{P} / \mathrm{D}$, due to the increase of fuel volume fraction; (2) maximum cladding interface temperature and maximum fuel temperature increase with fuel rod number and $\mathrm{P} / \mathrm{D}$, while the pressure drop increases with the fuel rod number and decreases with the increase of P/D. Core depletion results show that $k_{\text {eff }}$ of the equilibrium cycle parabolically varies with the fuel shuffling period, while the burn-up increases linearly. $k_{\text {eff }}$ of the equilibrium cycle for the outward fuel shuffling is greater than that of the inward one when fuel shuffling period is long. Minimum $k_{\text {eff }}$ during the whole life parabolically varies with the fuel shuffling period. Minimum $k_{\text {eff }}$ of the inward fuel shuffling core during the whole life is greater than that of the outward one when fuel shuffling period is short. Power peaking factor of the inward fuel shuffling strategy decreases with the fuel shuffling period exponentially, while that of the outward fuel shuffling strategy increases with the fuel shuffling period exponentially. Power distribution of the inward and outward fuel shuffling core varies with core operation. In comparison, the outward fuel shuffling core with fuel shuffling period of 500 days is the optimized design. Preliminary thermal-hydraulic analysis of the optimized design core shows that the maximum 
cladding interface temperature and maximum fuel temperature are all within the limits for BOL, BOEC and EOEC. Main parameters of the optimized design core have been calculated for further safety analysis.

\section{Acknowledgments}

This research work is supported by National Science Foundation of China (Grant No. 11125522) and Innovative Research Team in University of Ministry of Education of China (Grant No. IRT1280) 


\section{References}

Chen, X. N., Kiefhaber, E., Maschek, W., 2008. Fundamental burn-up mode in a pebblebed type reacor. Progress in Nuclear Energy 50, 219-224.

Chen, X. N., Zhang, D. L., Maschek, W., 2011. Fundamental burn-up modes of radial fuel shuffling. In: M\&C'11, Rio de Janeiro, RJ, Brazil, May 8-12, 2011.

Chen, X. N., Kiefhaber, E., Zhang, D. L., 2012. Fundamental solution of nuclear solitary wave. Energy Conversion and Management 59, 40-49.

Feinberg, S. M., 1958. Nuclear power plant: Part 2. Discussion. In: Proceedings of the 2nd UN International Conference on Peaceful Uses of Atomic Energy, United Nations, Geneva, Switzerland.

Feoktistov, L. P., 1988. Analysis of a concept of a physically safe reactor. Preprint IAE$4605 / 4$.

Fomin, S. P., Mel'nik, Yu. P., Pilipenko, V. V., 2008. Initiation and propagation of nuclear burning wave in fast reactor. Progress in Nuclear Energy 50, 163-169.

Greenspan, E., Heidet, F., 2009. Fast reactors for maximum fuel utilization without chemical reprocessing. In: Proceedings of ICENE'09, Ericeira, Portugal, June 29-July 3, 2009.

Greenspan, E., Heidet, F., 2011. Energy sustainability and economic stability with Breed and Burn reactors. Progress in Nuclear Energy 53, 794-799.

Heidet, F., Greenspan, E., 2012. Feasibility of lead cooled breed and burn reactors. Progress in Nuclear Energy 54, 75-80. 
Heidet, F., Greenspan, E., 2013. Performance of large breed and burn core. Nuclear Technology 181, 381-407.

Marshall, T., Parry, J., Weaver, K. D., 2005. Engineering and physics of a breed and burn fast reactor systems. INL/EXT-05-00886, INL, 2005.

Qvist, S., Greenspan, E., 2012. Inherent safety of minimum burnup Breed-and Burn Reactors. In: Proceedings of ICAPP'12, Chicago, USA, June 24-28, 2012.

Qvist, S., Greenspan, E., 2014. The ADOPT code for automated fast reactor core design. Annals of Nuclear Energy 71, 23-36.

Seifritz, W., 2000. Solitary burn-up waves in a multiplying medium. Kerntechnik 65, $5-6$.

Sekimoto, H., Ryu, K., Yoshimura, Y., 2001. CANDLE: the new burnup strategy. Nuclear Science and Engineering 139, 306-317.

Teller, E., Ishikawa, M., Wood, L., 1996. Completely automated nuclear reactors for long-term operation. In: Proceedings of the ICENES'96. Obninsk, Russia, June 2428,1996 .

Van Dam, H., 2003. Flux distributions in stable criticality waves. Annals of Nuclear Energy 30, 1495-1504.

Zhang, D. L., Chen, X. N., Flad, M., et al., 2013. Theoretical and numerical studies of TWR based on ESFR core design. Energy Conversion and Management 72, 12-18.

Zheng, M. Y., Tian, W. X., Chu, X., et al., 2014a. Design of a radial fuel shuffling sodium cooled TWR core and steady analysis. In: Proceedings of the 2014 22th 
International Conference on Nuclear Engineering, PRAGUE, CZECH REPUBLIC, July 7-11, 2014.

Zheng, M. Y., Tian, W. X., Chu, X.., et al., 2014b. Preliminary design study of a board type radial fuel shuffling sodium cooled breed and burn reactor core. Nuclear Engineering and Design 278C, 679-685.

Zheng, M. Y., Tian, W. X., Wei, H. Y., et al., 2014c. Development of a MCNP-ORIGEN burn-up calculation code system and its accuracy assessment. Annals of Nuclear Energy 63, 491-498.

Zheng, M. Y., Tian, W. X., Chu, X., et al., 2015. Minor actinide transmutation in a board type sodium cooled breed and burn reactor core. Annals of Nuclear Energy 81, 41-49. 


\section{Figure list}

Fig. 1 Axial and radial diagram of assembly

Fig. 2 Flow diagram of SAST

Fig. 3 Core layout in radial view of design A

Fig. 4 Core layout in radial view of design B

Fig. 5 Core and surrounding layout in section view

Fig. 6 Fuel shuffling strategy

Fig. 7 Assembly numeration of the $1 / 6$ core for burn-up simulation

Fig. $8 k_{\infty}$ evolution of different P/D assemblies

Fig. 9 Neutron balance as a function of burn-up

Fig. 10 Maximum cladding interface temperature as a function of fuel rod number and $\mathrm{P} / \mathrm{D}$

Fig. 11 Maximum fuel temperature as a function of fuel rod number and P/D

Fig. 12 Pressure drop as a function of fuel rod number and P/D

Fig. $13 k_{\text {eff }}$ during operation for fuel shuffling period of 500 days

Fig. $14 k_{\text {eff }}$ of equilibrium cycle as a function of fuel shuffling period

Fig. 15 Minimum $k_{\text {eff }}$ during the whole life

Fig. 16 Radial power peaking factor as a function of fuel shuffling period

Fig. 17 Power distribution of inward fuel shuffling as a function of fuel shuffling period

Fig. 18 Power distribution of outward fuel shuffling as a function of fuel shuffling period 
Fig. 19 Power distribution of optimized fuel shuffling period for inward fuel shuffling

Fig. 20 Power distribution of optimized fuel shuffling period for outward fuel shuffling

Fig. 21 Average discharged burn-up as a function of fuel shuffling period

Fig. 22 Power distribution and flow groups

Fig. 23 Relative power flow ratio

Fig. 24 Temperature distribution of hot channels for the optimized core design 


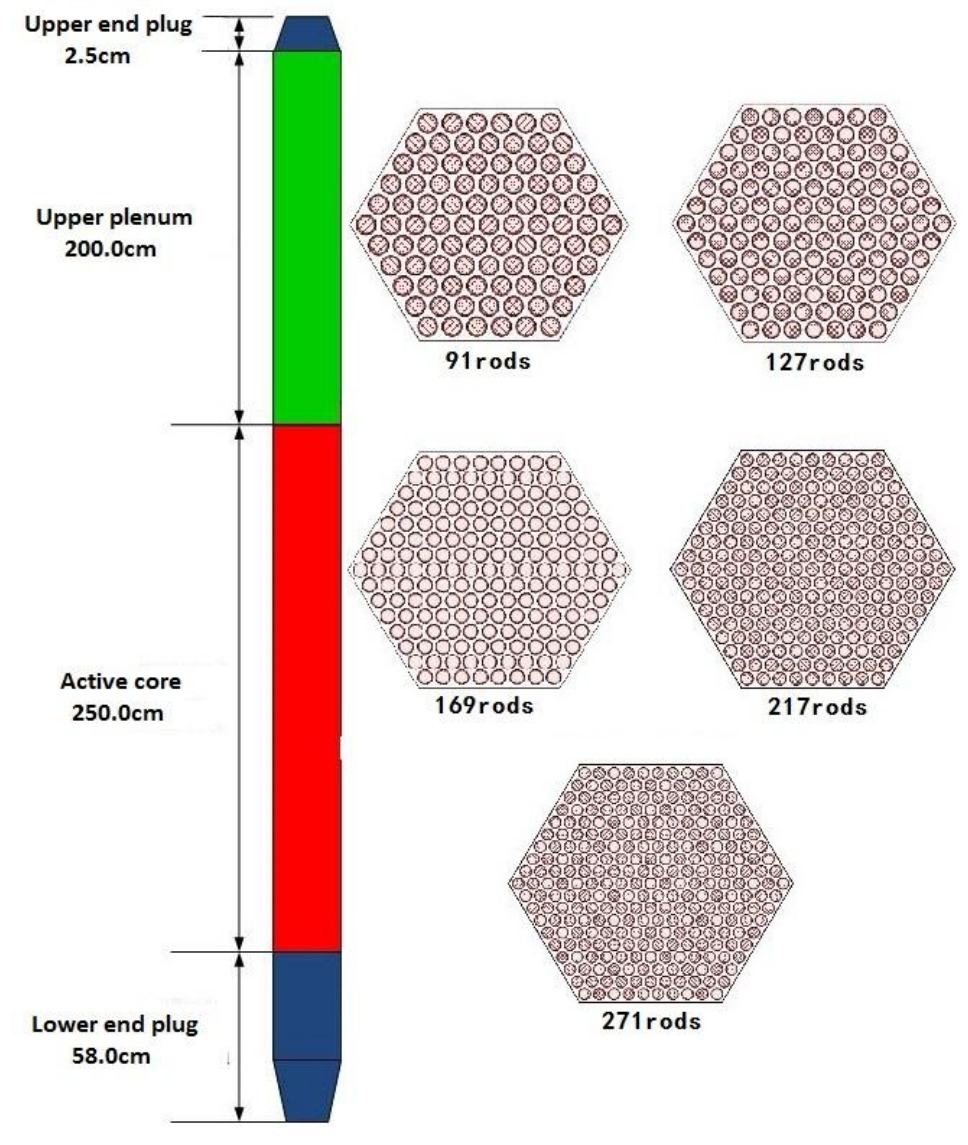

Fig. 1 Axial and radial diagram of assembly

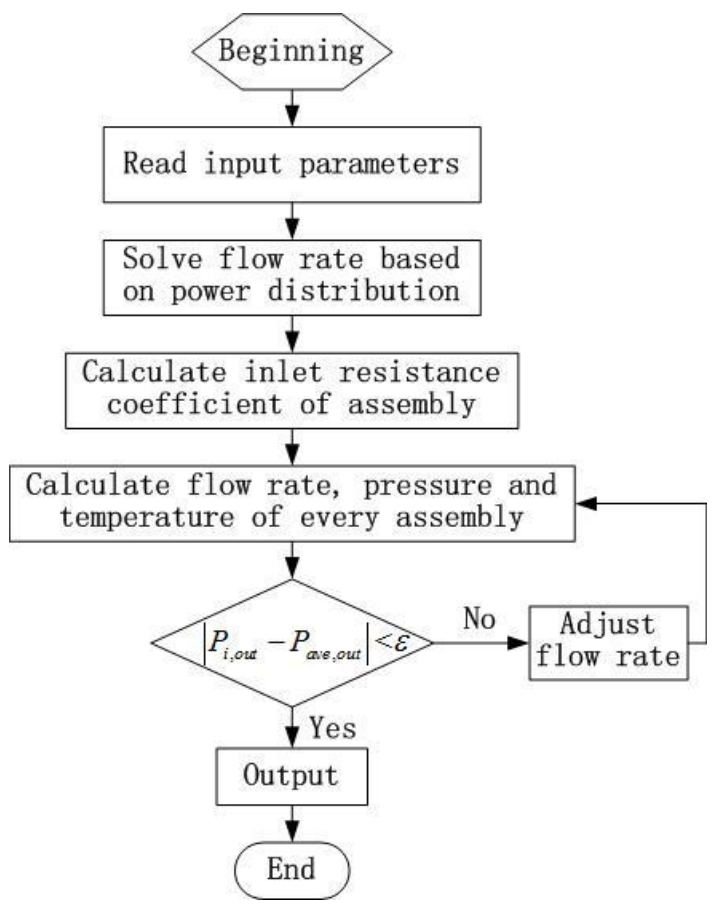

Fig. 2 Flow diagram of SAST 


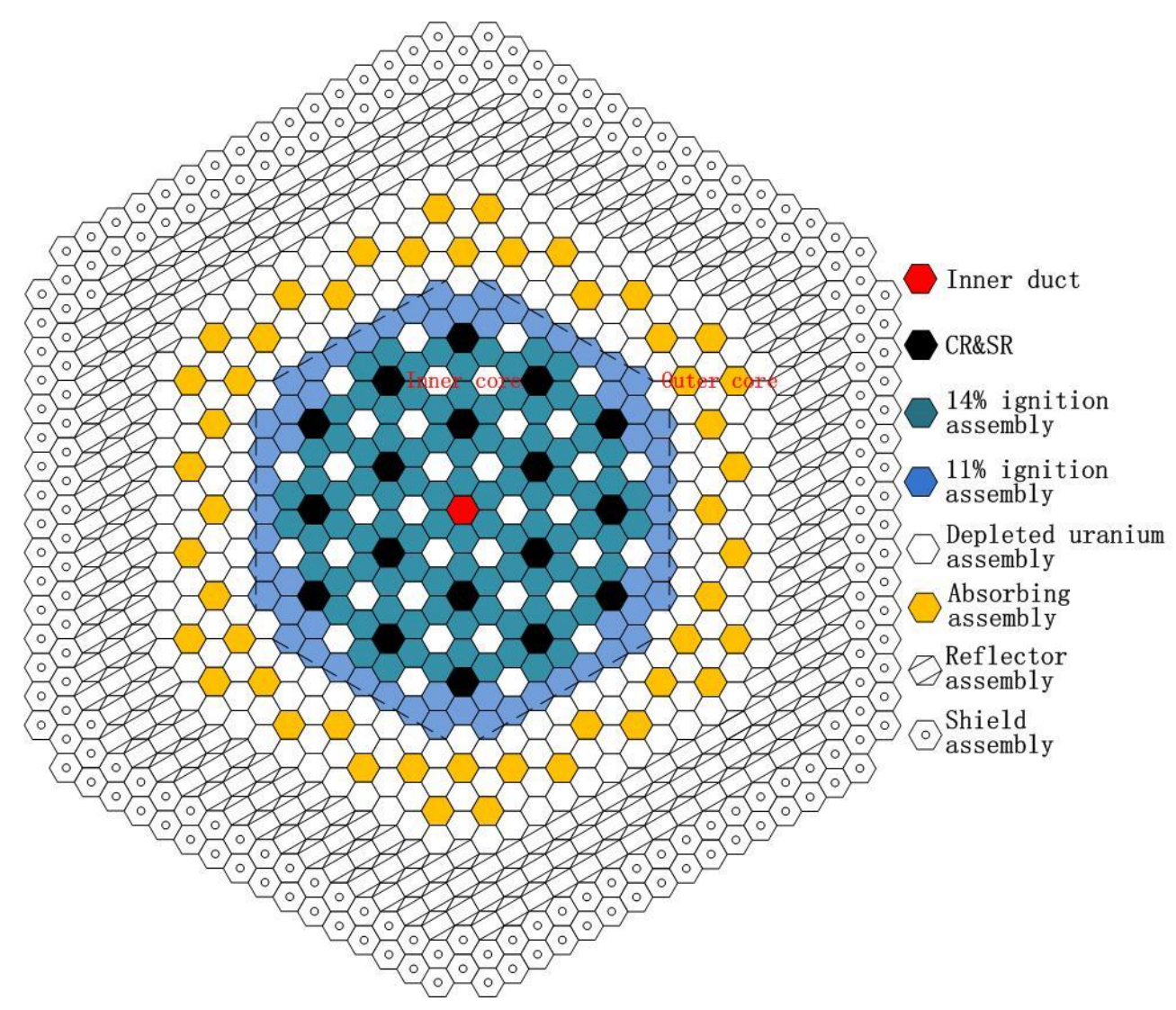

Fig. 3 Core layout in radial view of design A

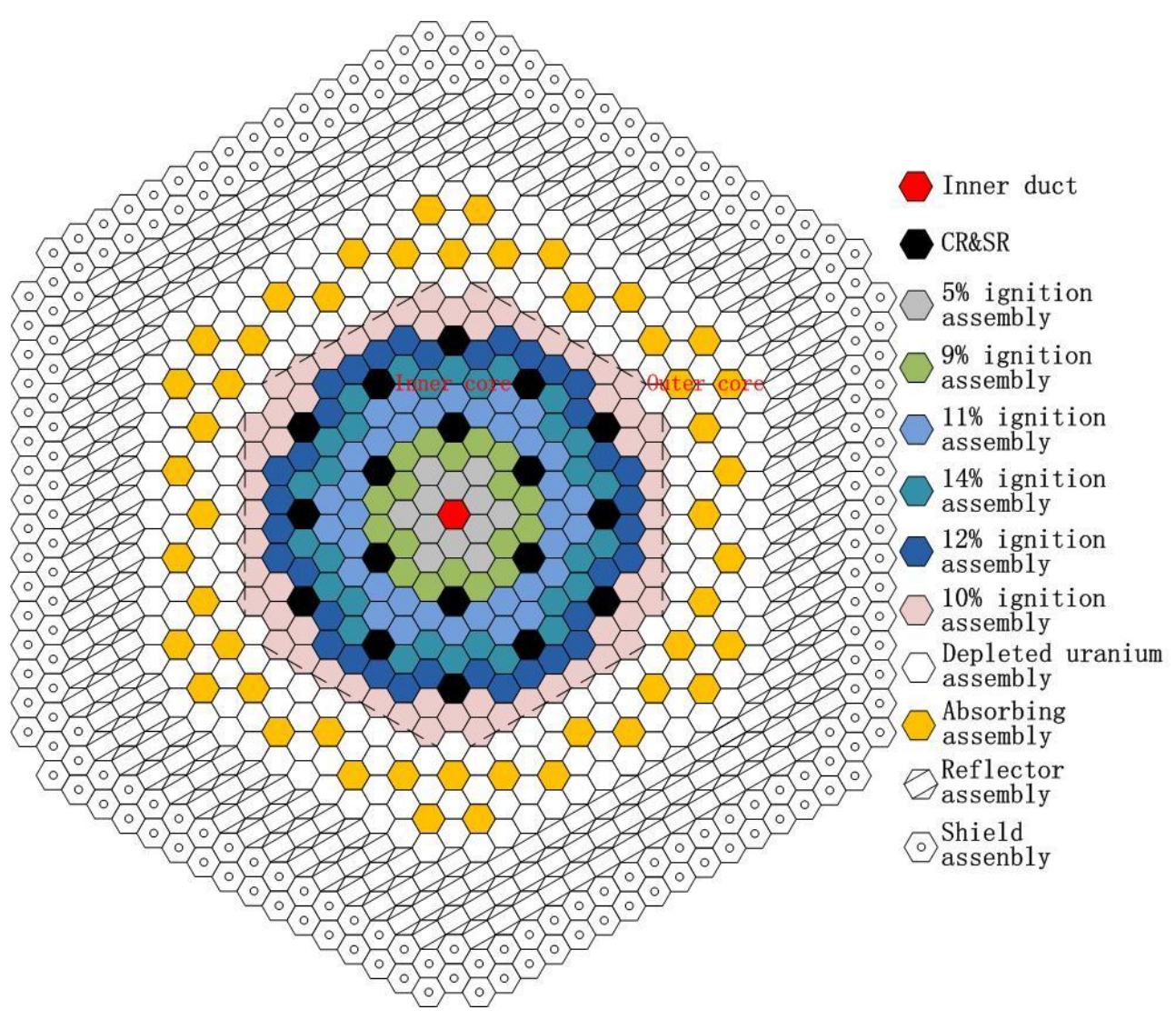


Fig. 4 Core layout in radial view of design B

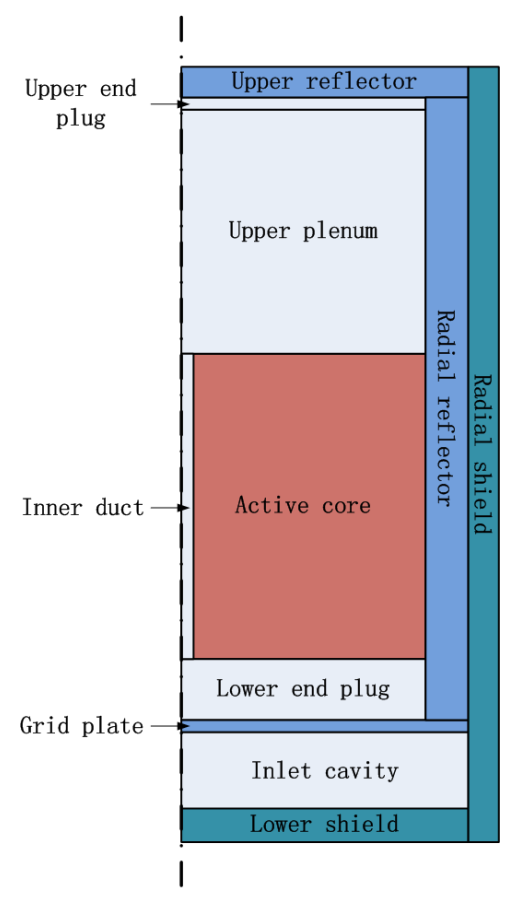

Fig.5 Core and surrounding layout in section view

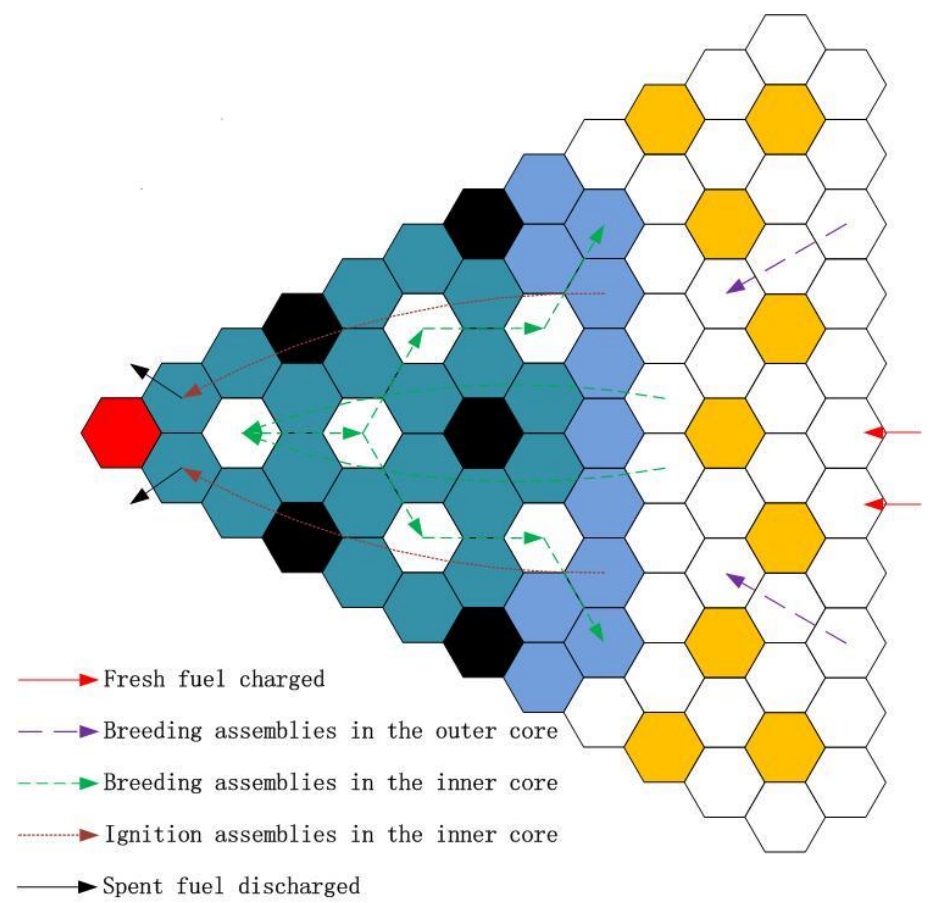

(a) Inward fuel shuffling 


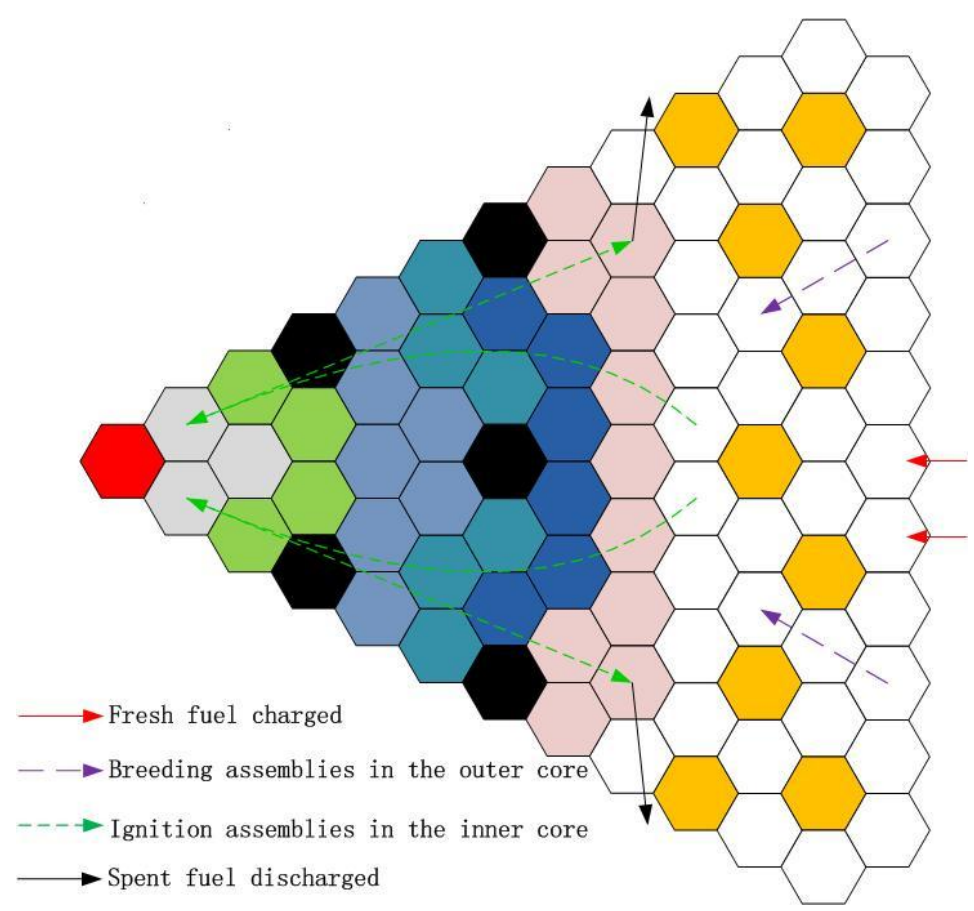

(b) Outward fuel shuffling

Fig.6 Fuel shuffling strategy

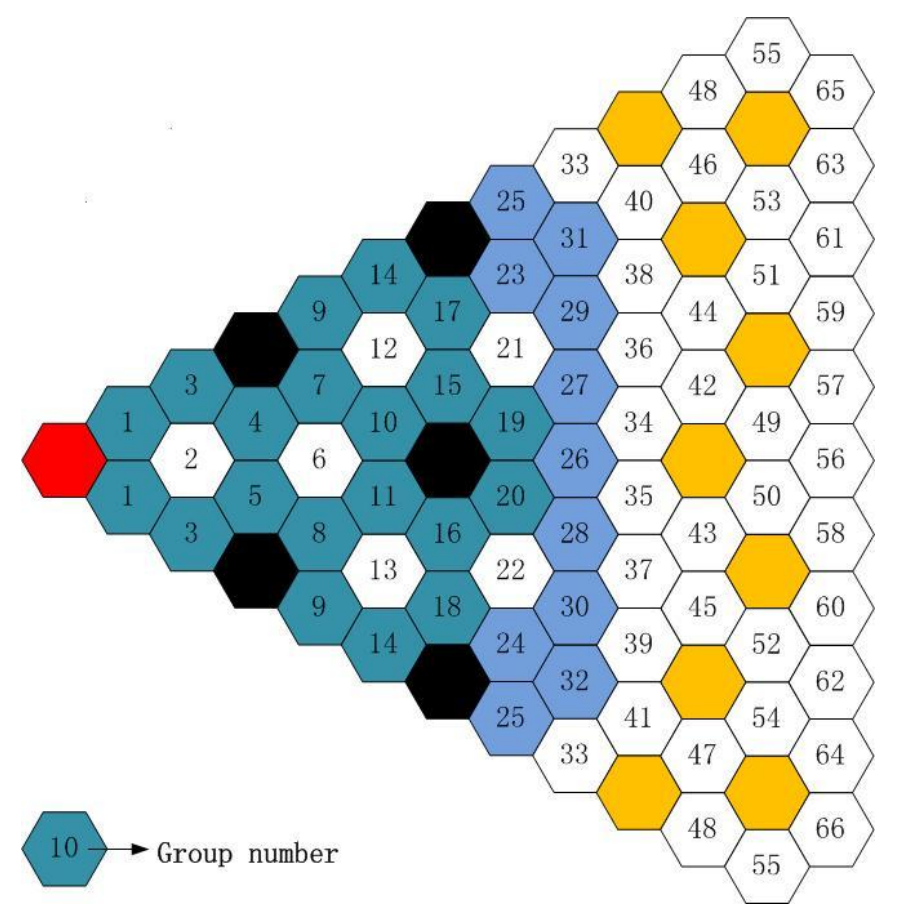

(a) Inward fuel shuffling core 


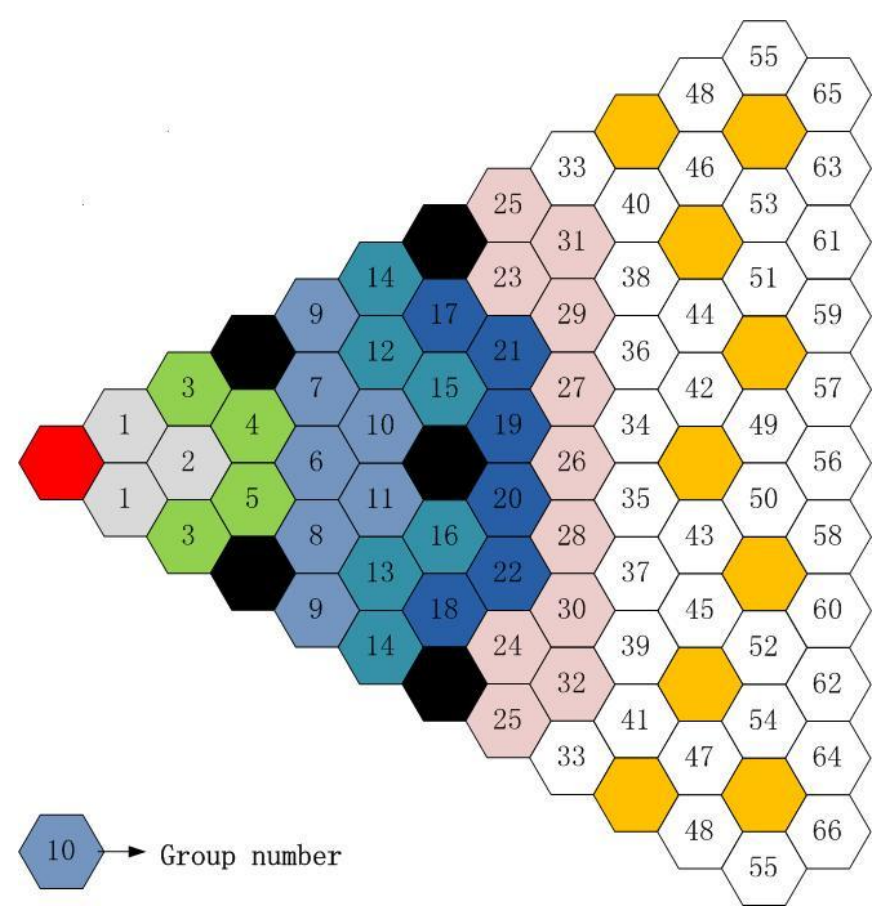

(b) Outward fuel shuffling core

Fig.7 Assembly numeration of the 1/6 core for burn-up simulation

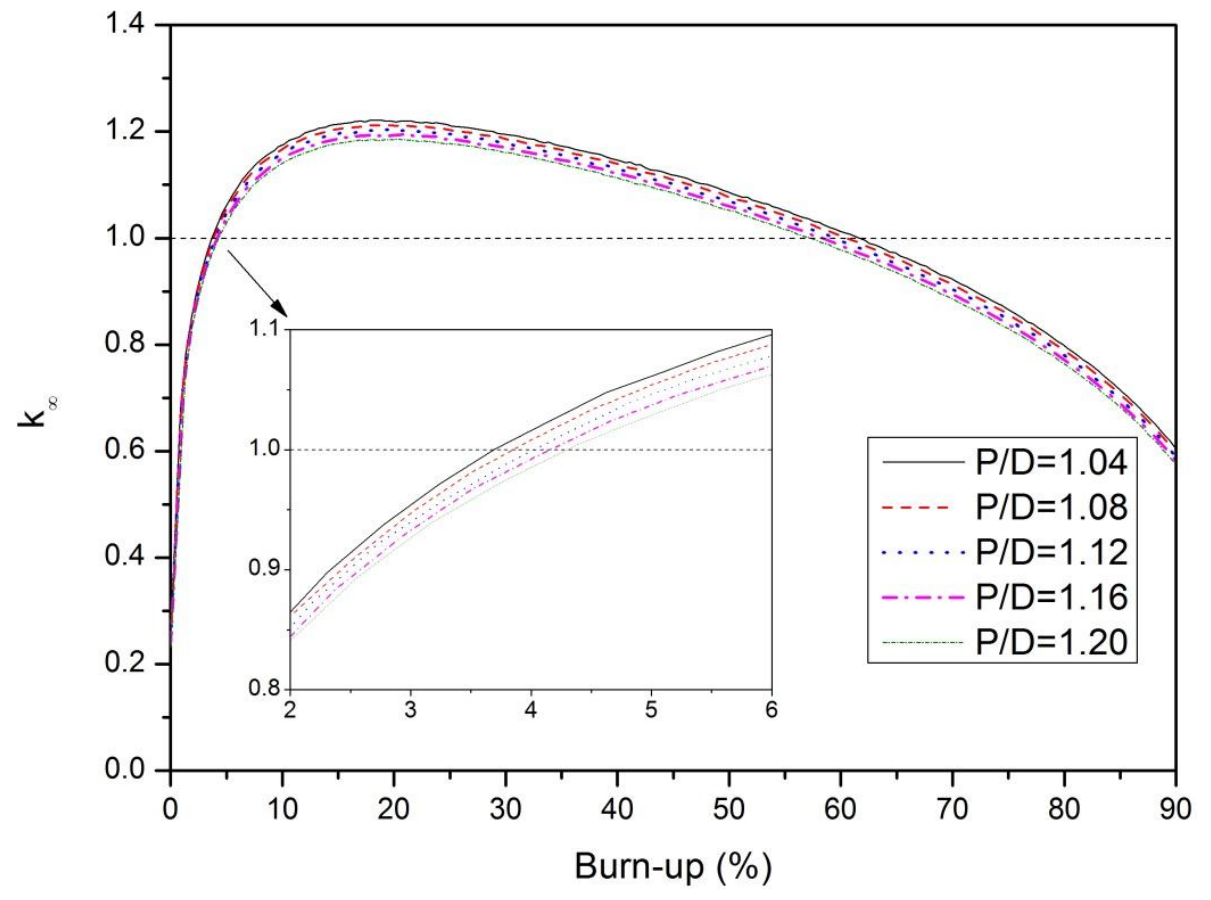

Fig.8 $k_{\infty}$ evolution of different P/D assemblies 


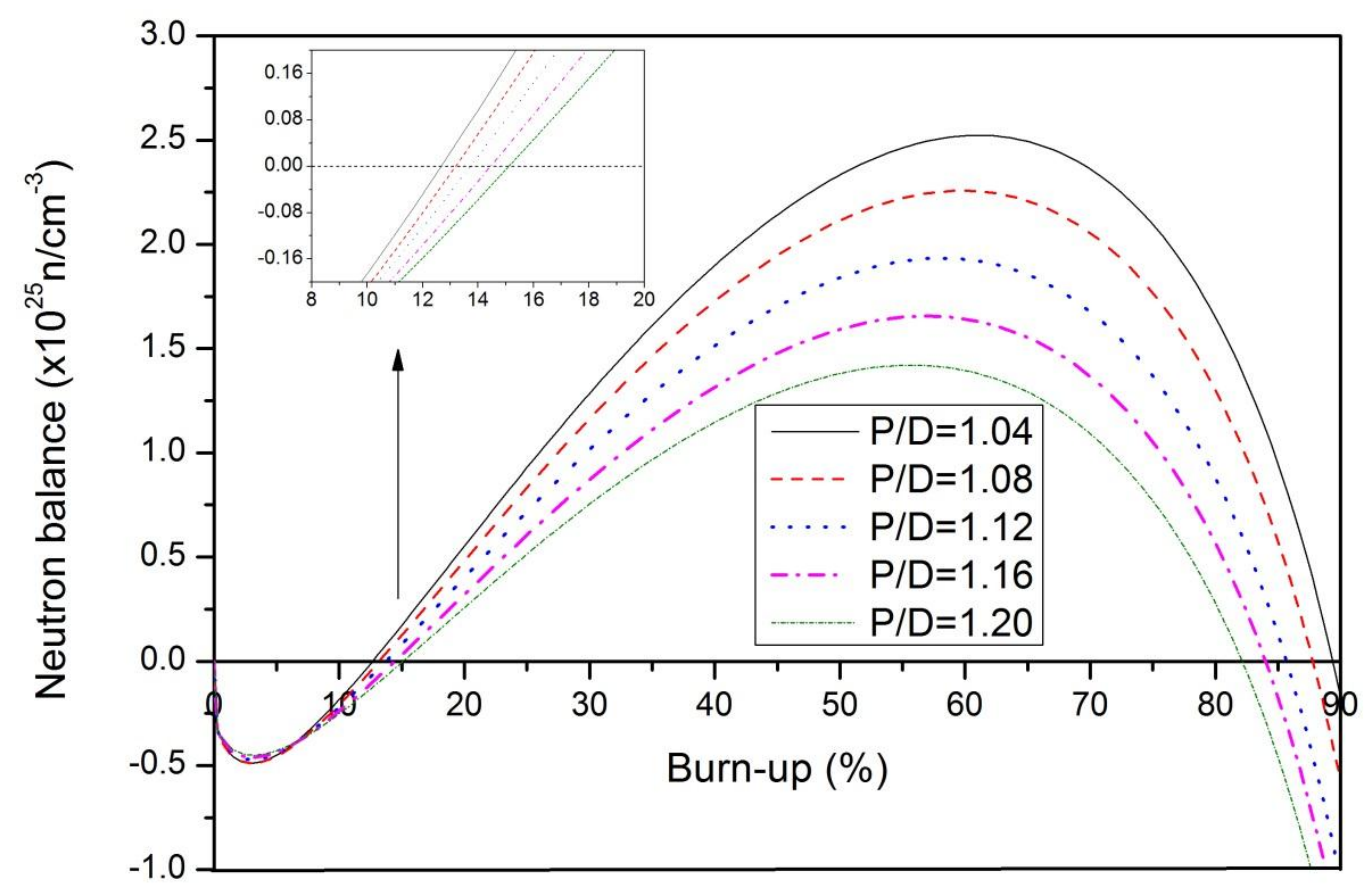

Fig.9 Neutron balance as a function of burn-up

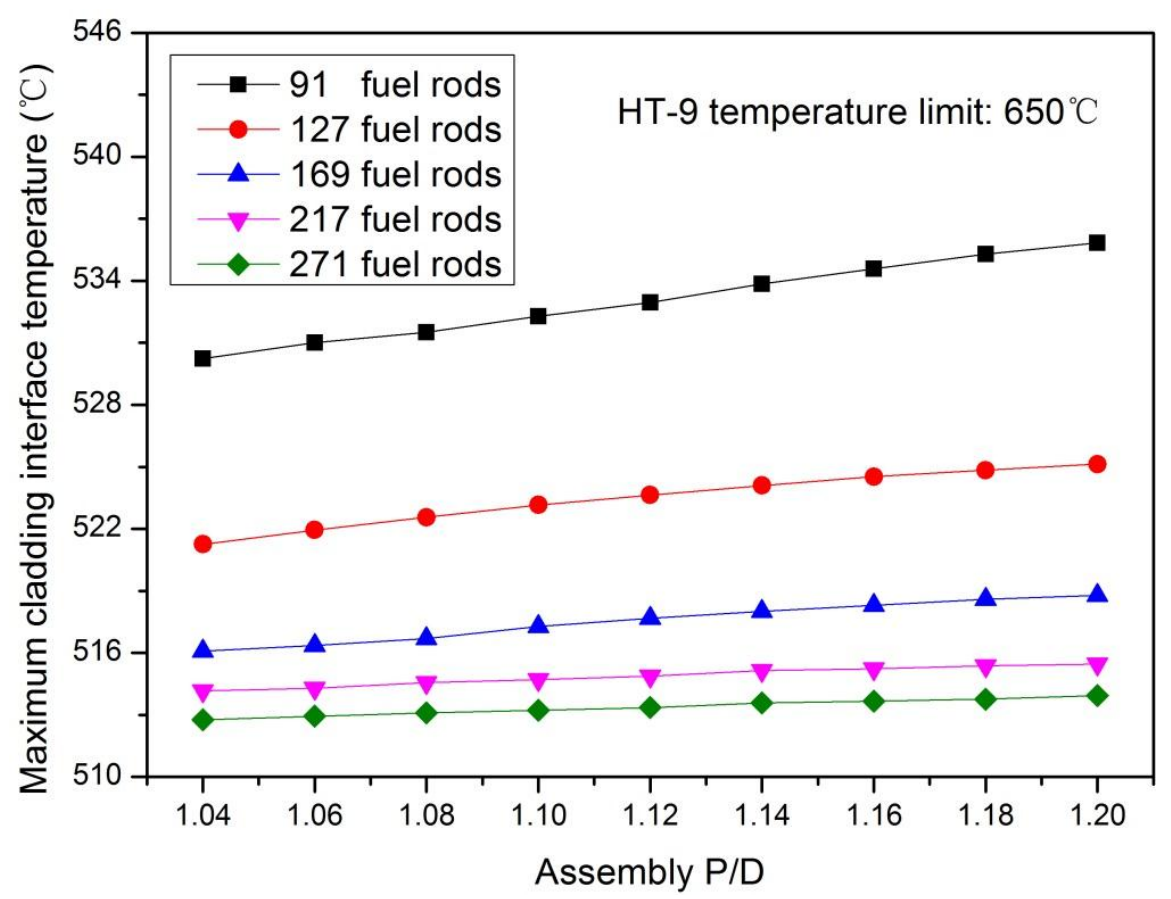

Fig. 10 Maximum cladding interface temperature as a function of fuel rods number and $\mathrm{P} / \mathrm{D}$ 


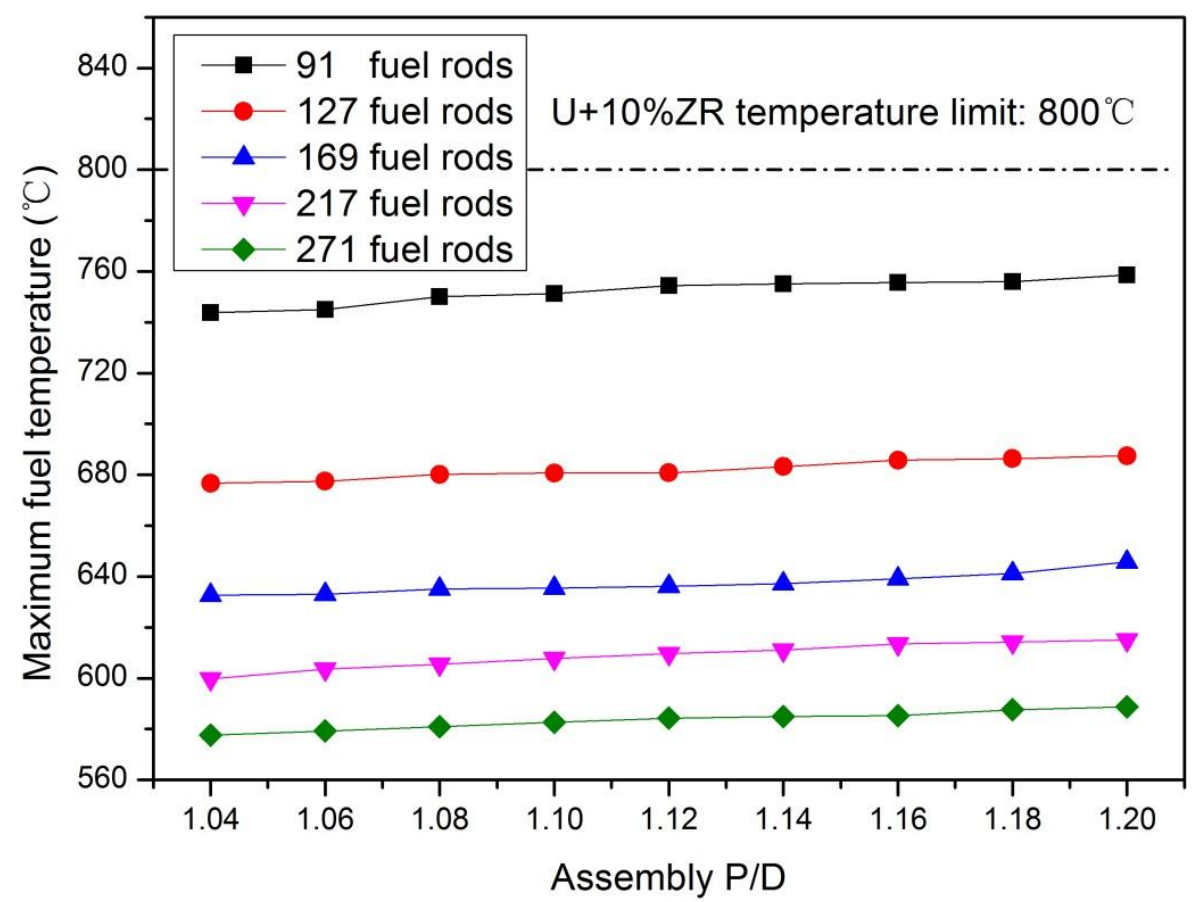

Fig. 11 Maximum fuel temperature as a function of fuel rods number and P/D

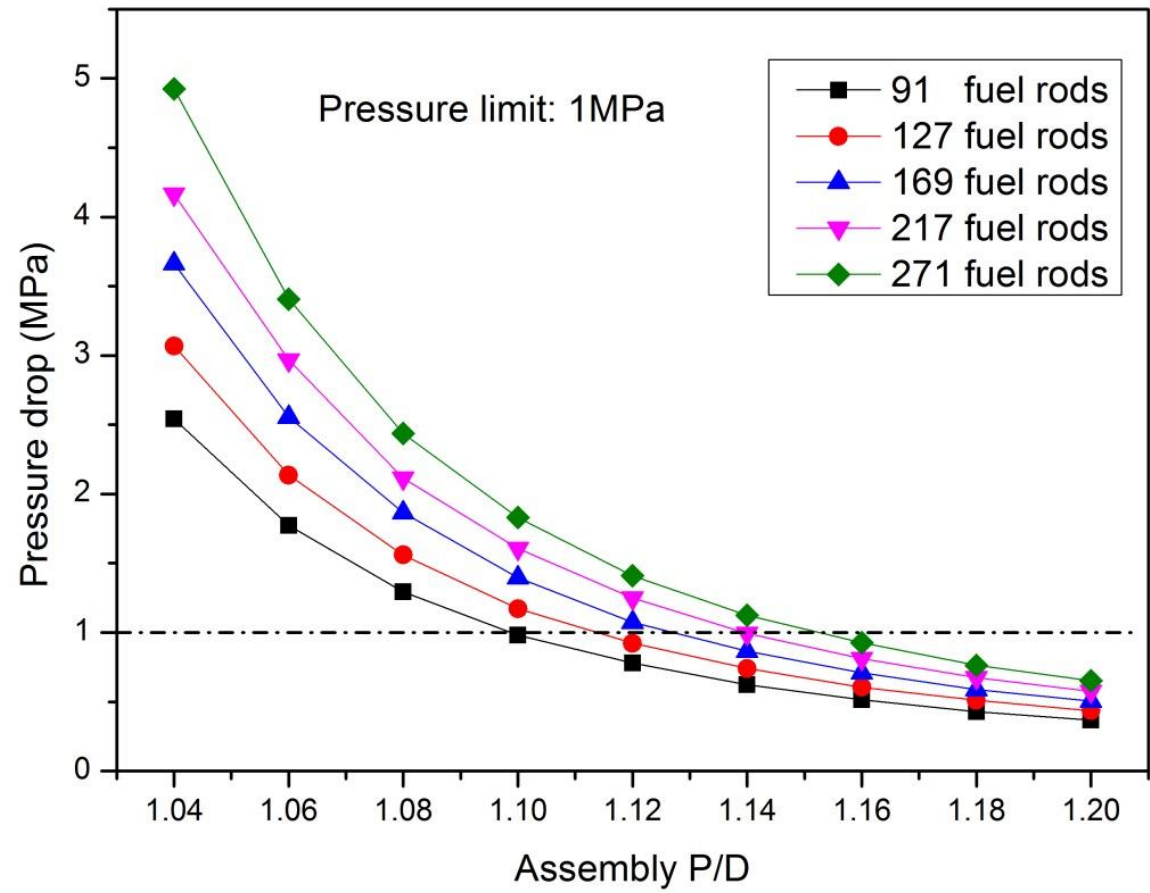

Fig. 12 Pressure drop as a function of fuel rods number and P/D 


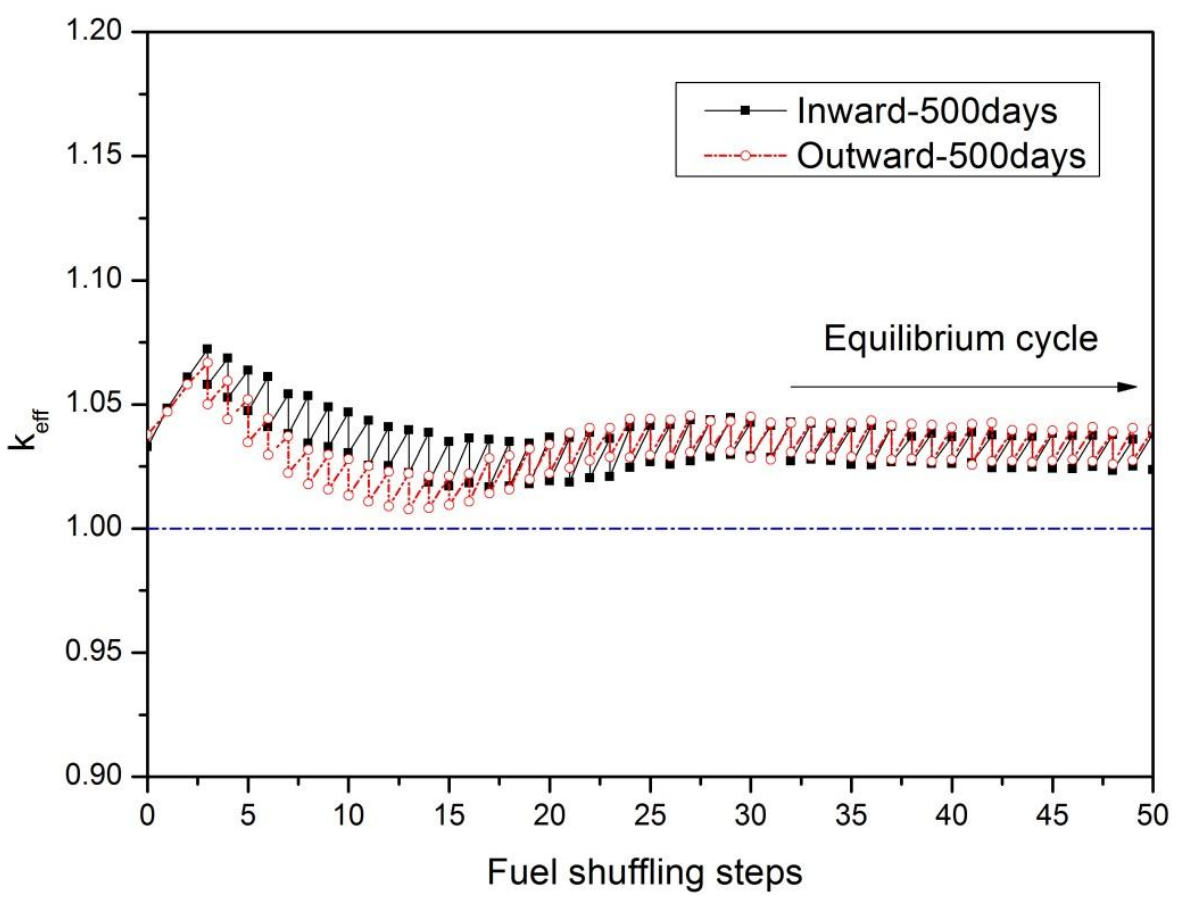

Fig. $13 k_{\text {eff }}$ during operation for fuel shuffling period of 500 days

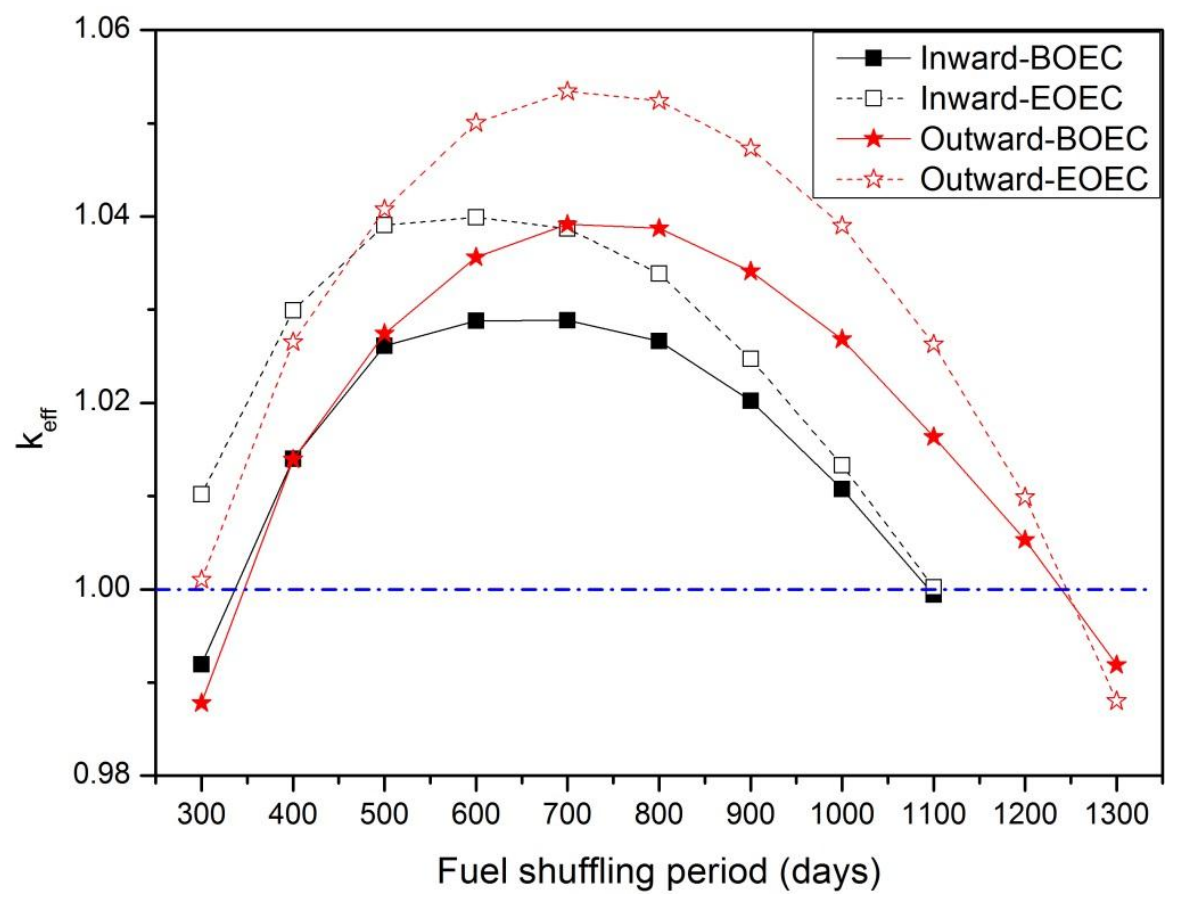

Fig. $14 k_{\text {eff }}$ of equilibrium cycle as a function of fuel shuffling period 


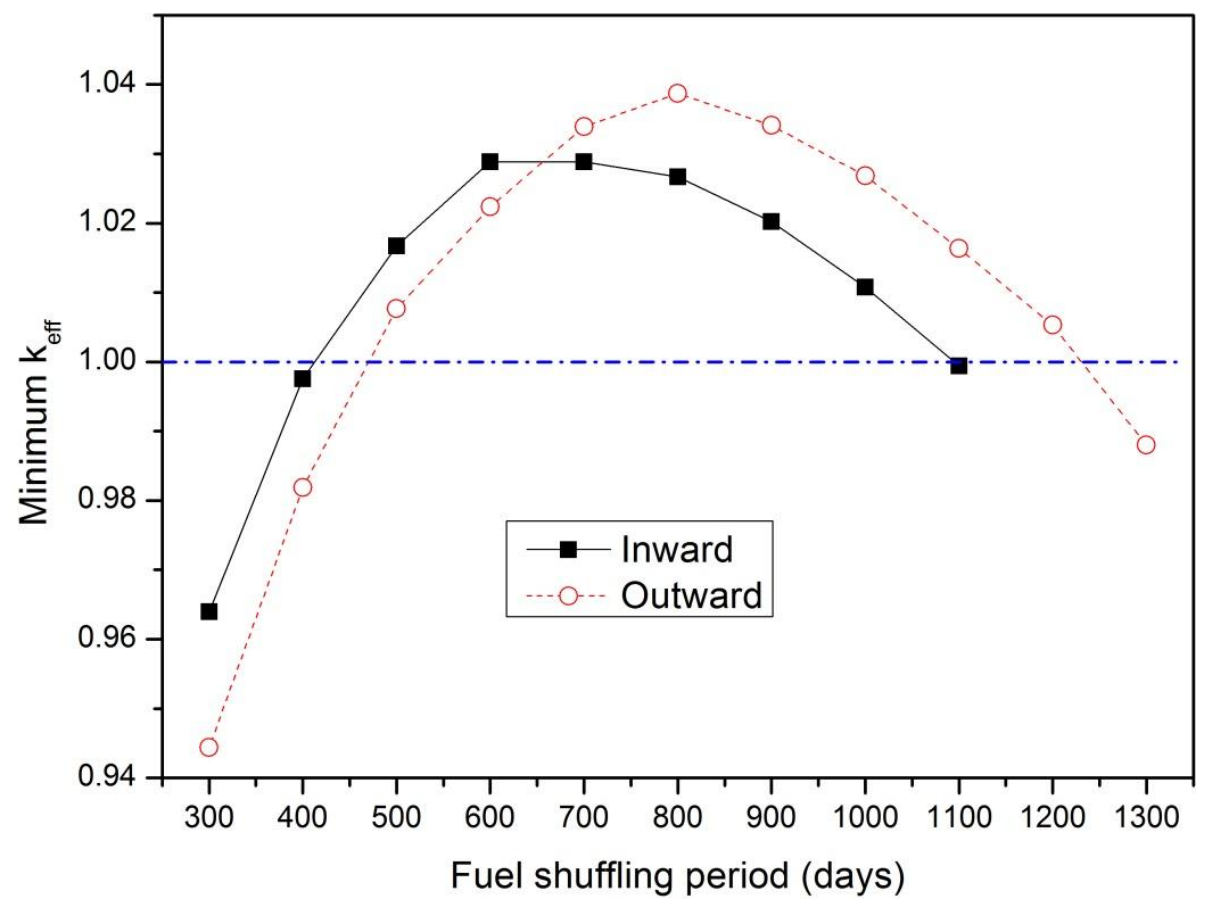

Fig. 15 Minimum $k_{\text {eff }}$ during the whole life

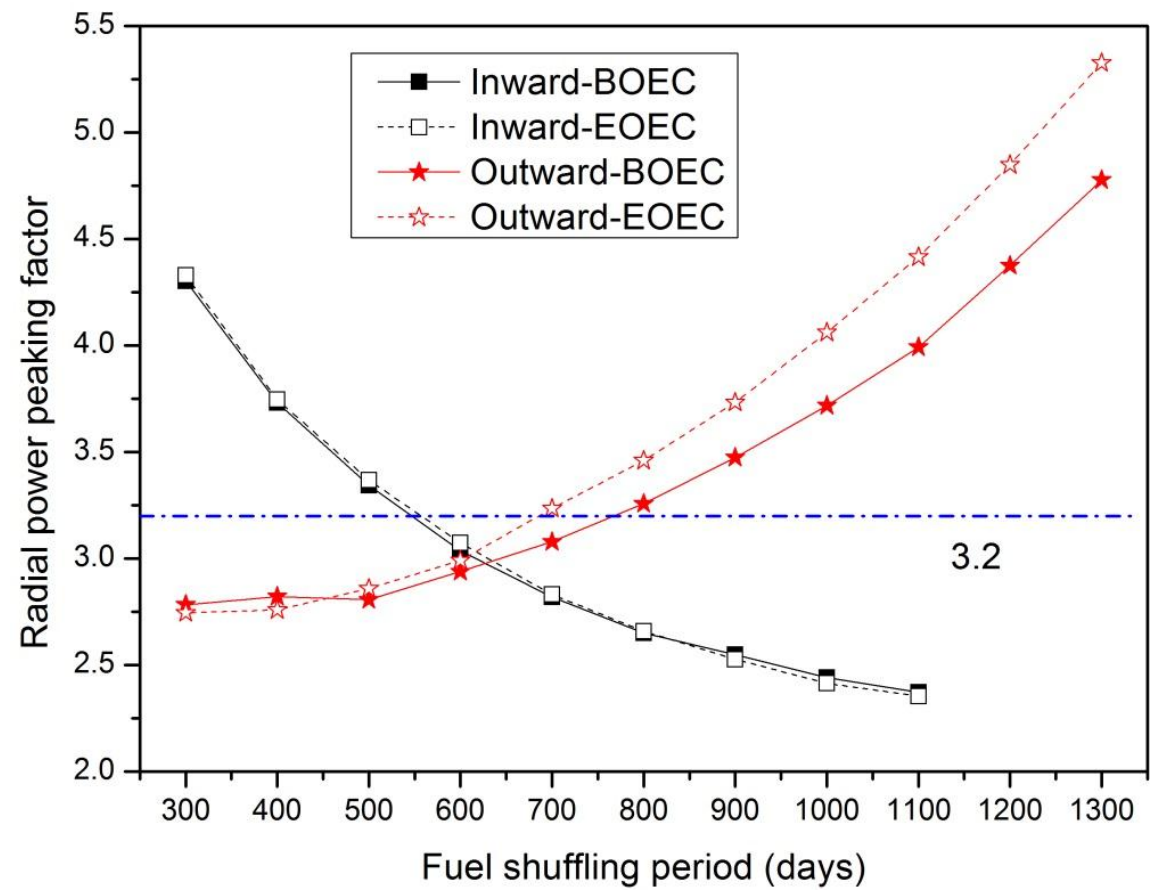

Fig. 16 Radial power peaking factor as a function of fuel shuffling period 


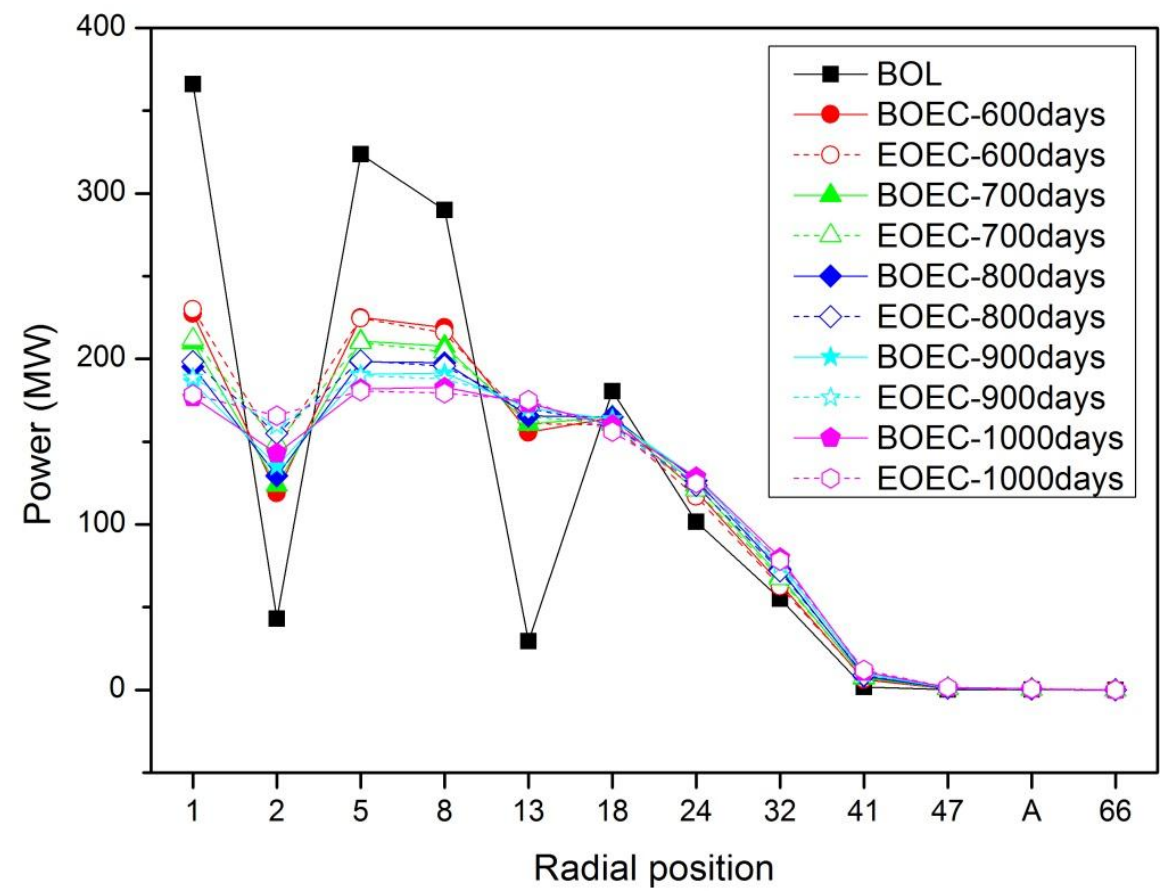

Fig. 17 Power distribution of inward fuel shuffling as a function of fuel shuffling

period

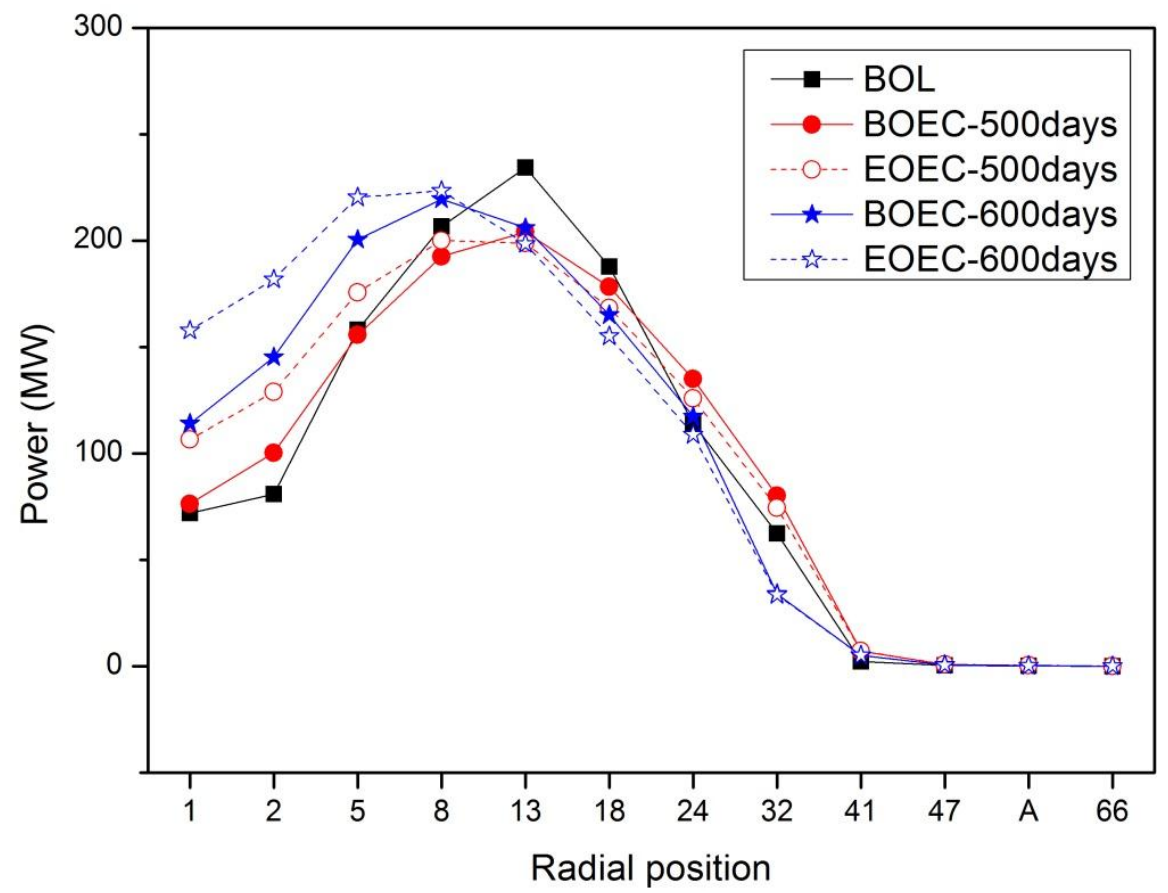

Fig. 18 Power distribution of outward fuel shuffling as a function of fuel shuffling period 


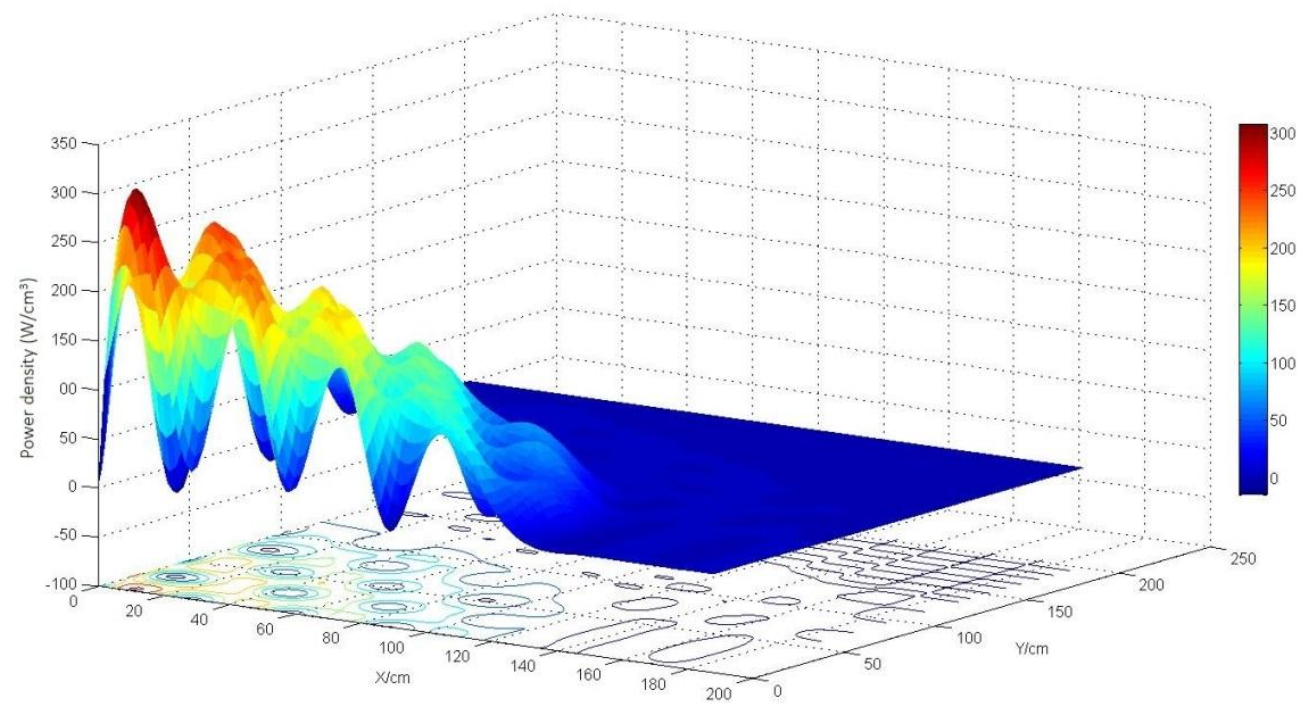

(a) BOL

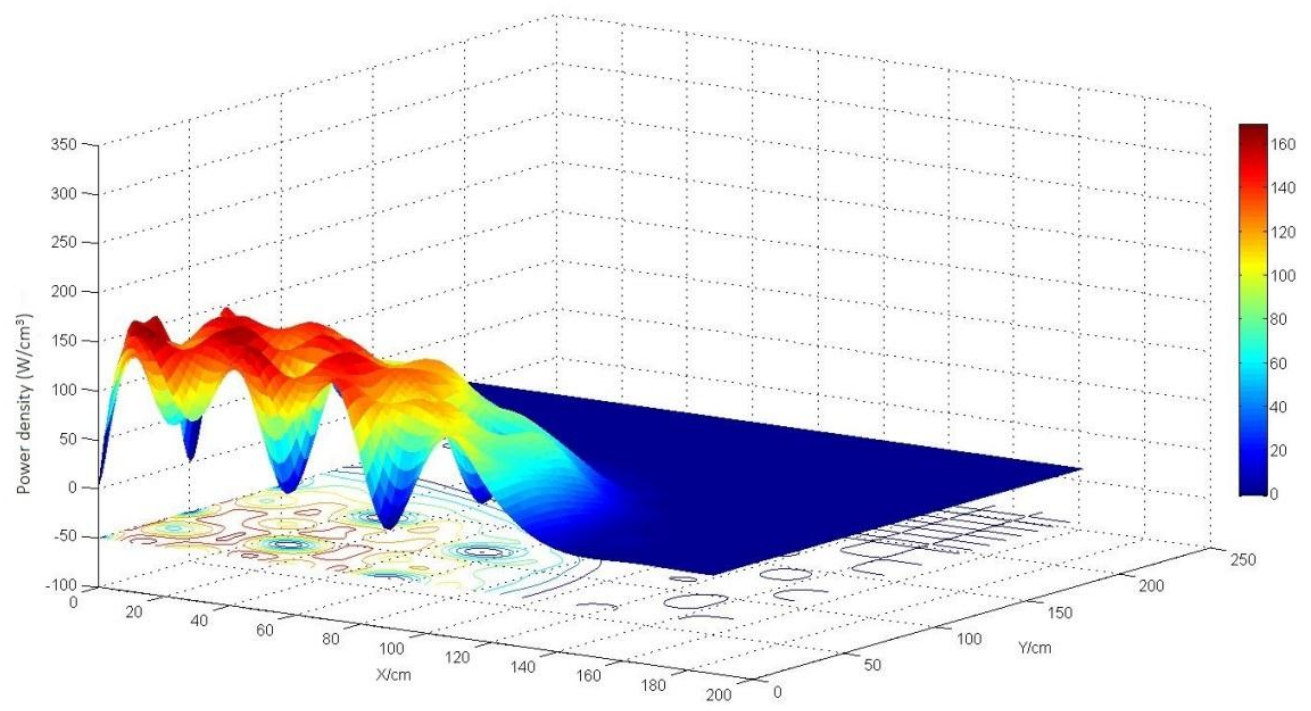

(b) BOEC 


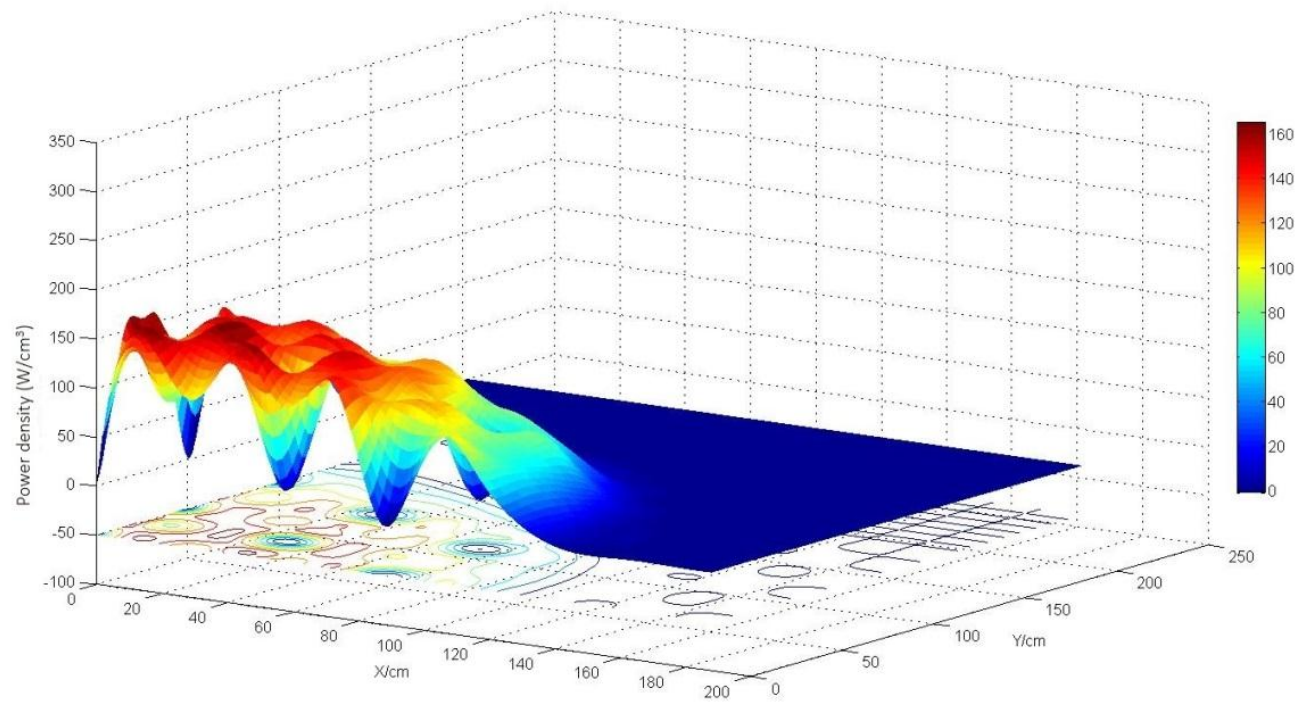

(c) EOEC

Fig. 19 Power distribution of optimized fuel shuffling period for inward fuel shuffling

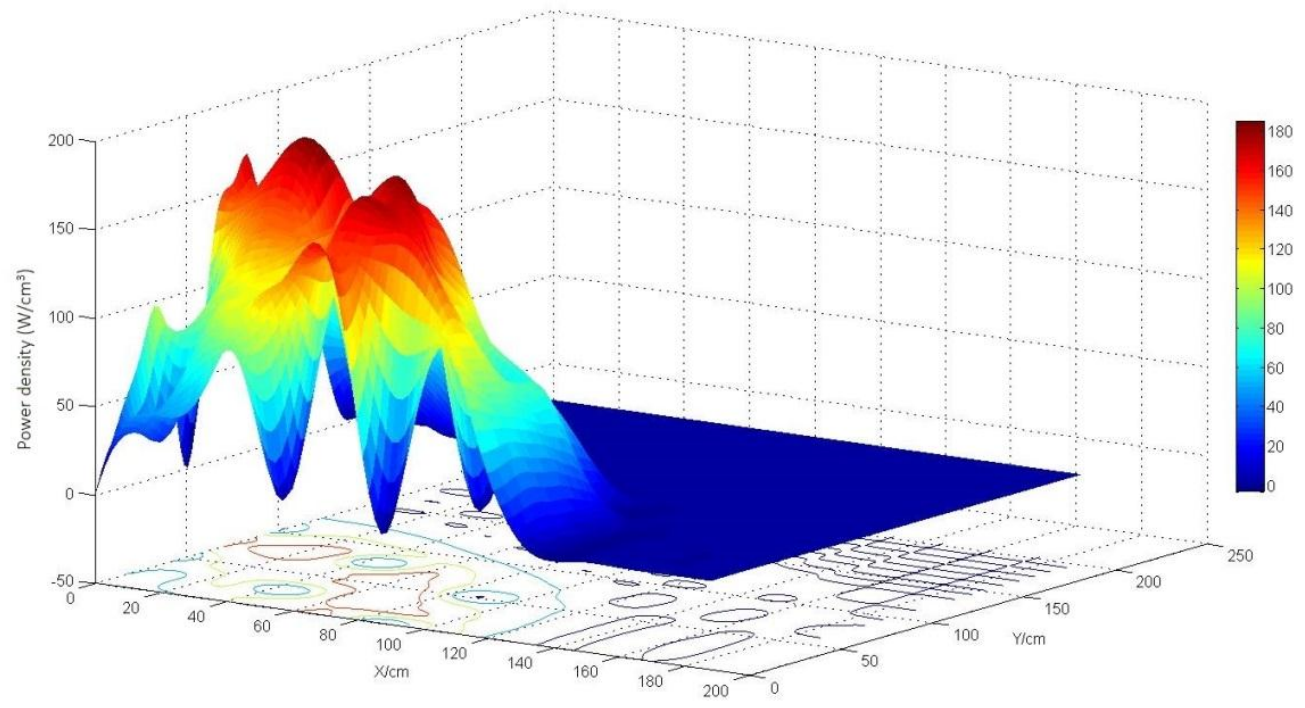

(a) $\mathrm{BOL}$ 


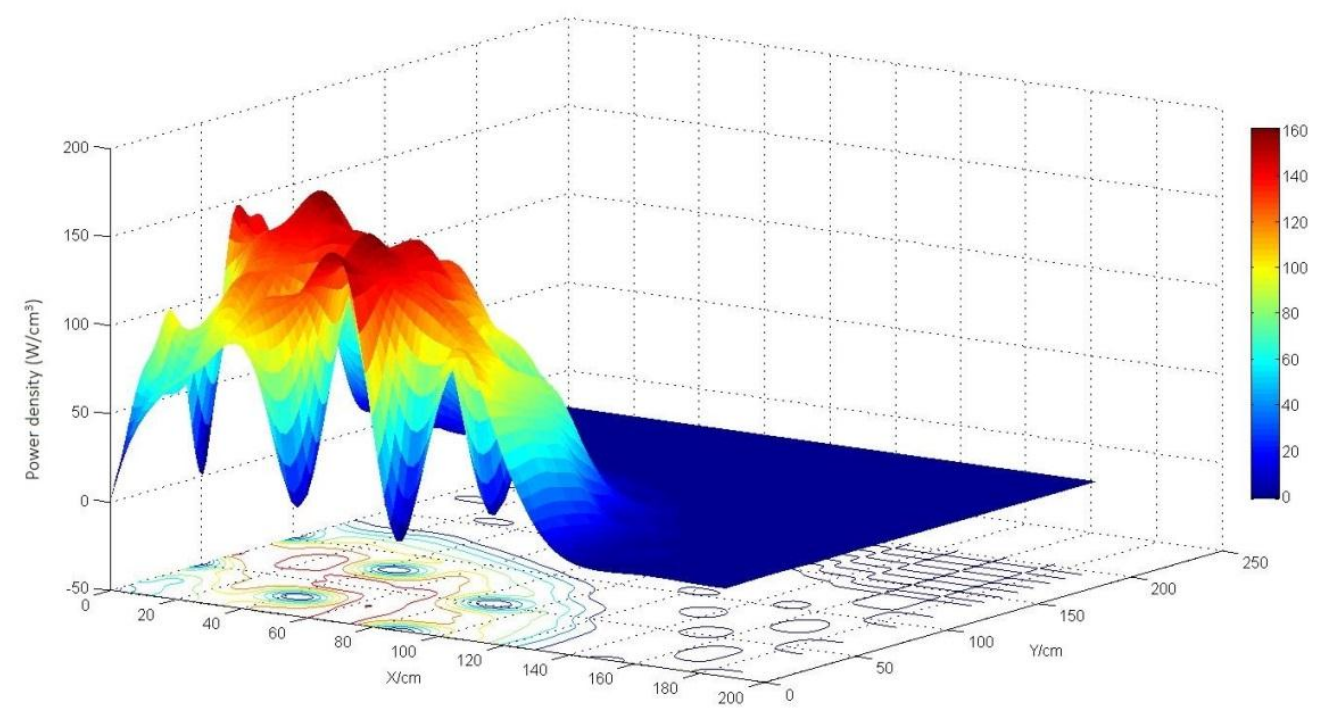

(b) BOEC

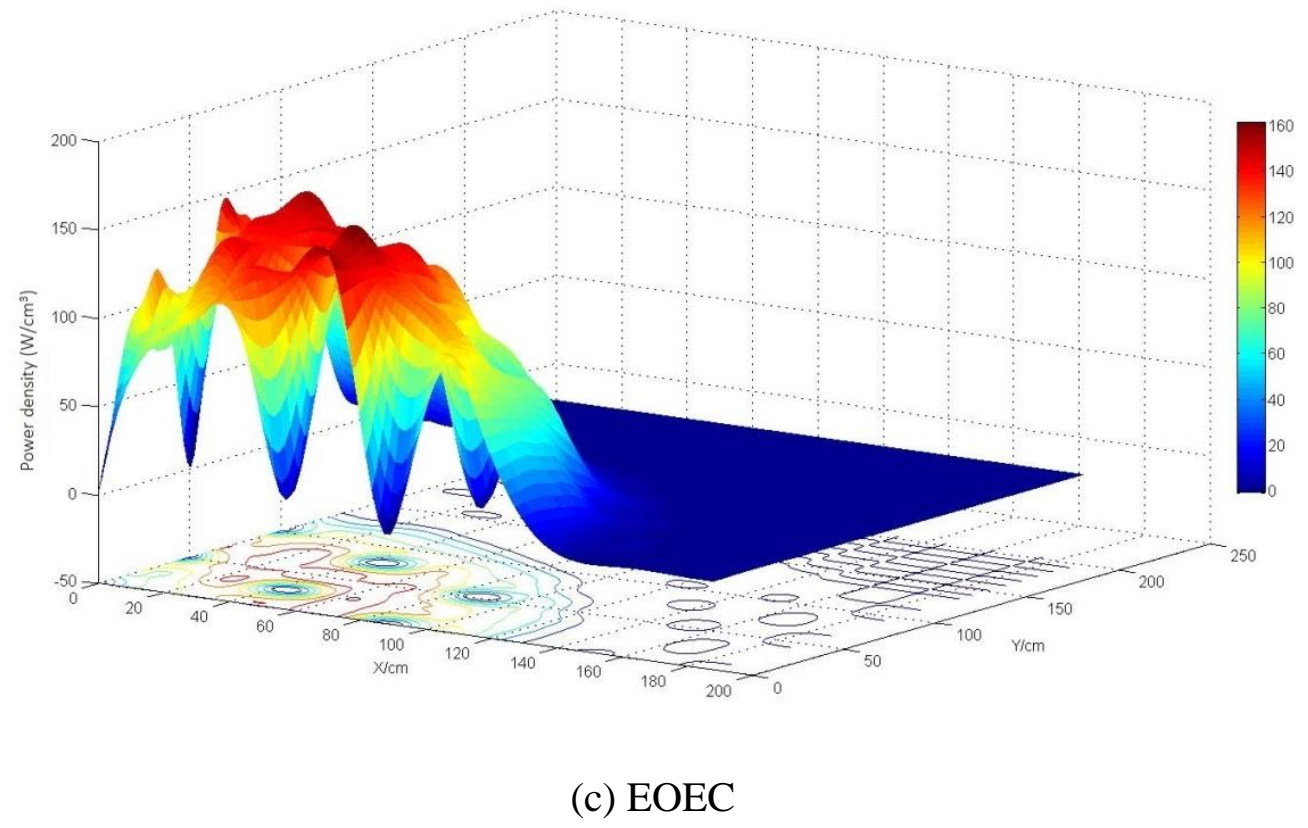

Fig. 20 Power distribution of optimized fuel shuffling period for outward fuel

shuffling 


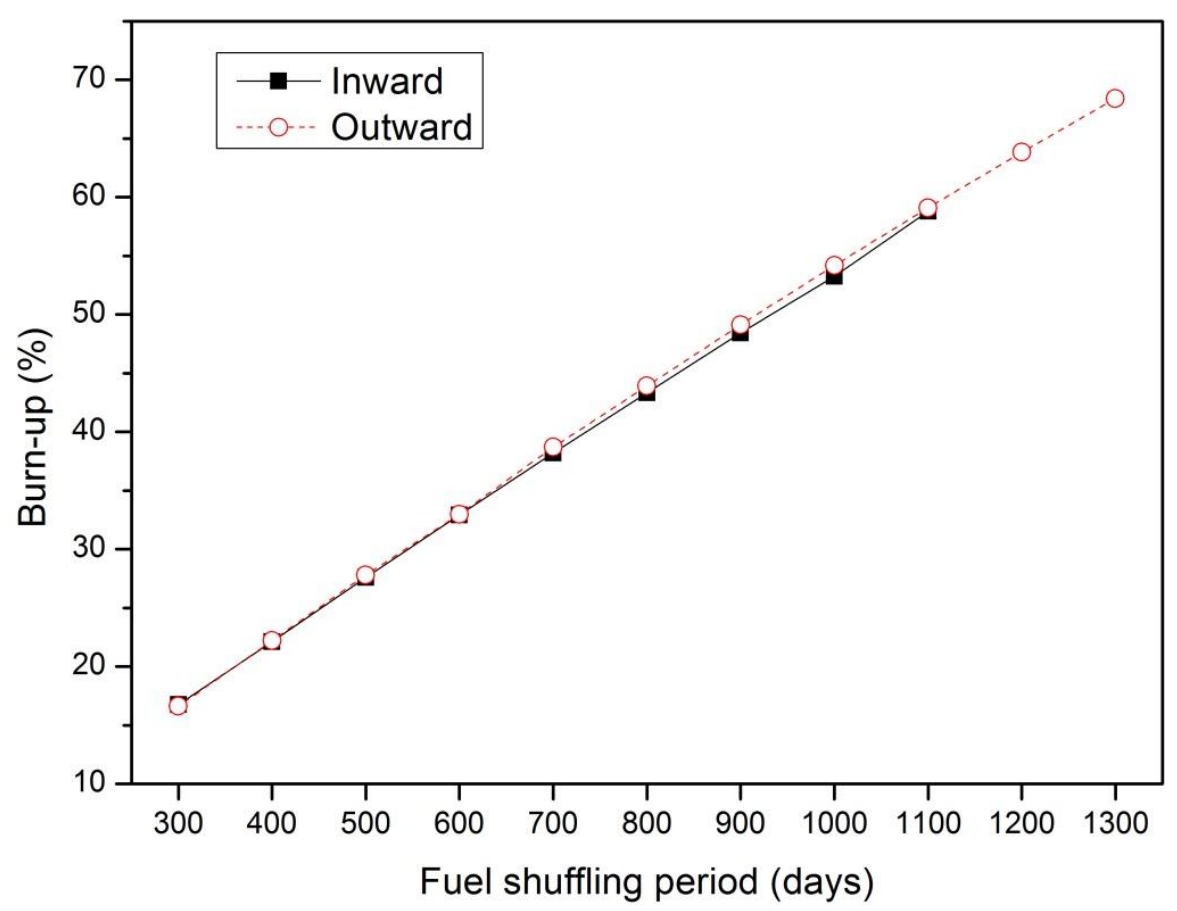

Fig. 21 Average discharged burn-up as a function of fuel shuffling period

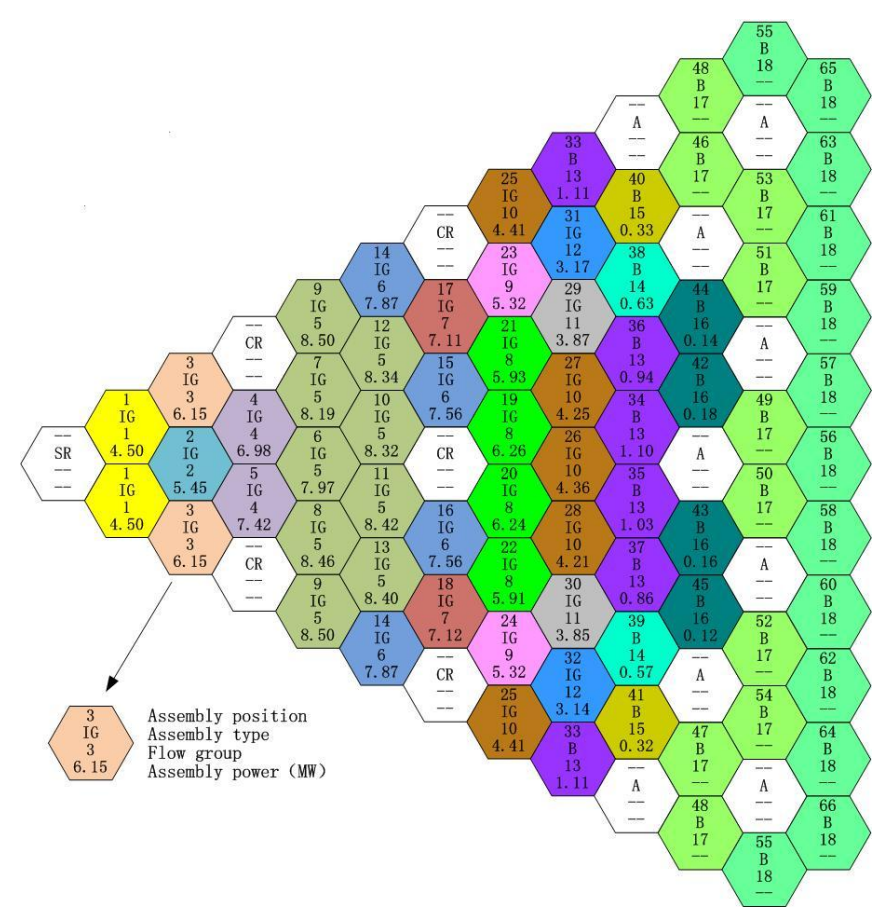

Fig. 22 Power distribution and flow groups 


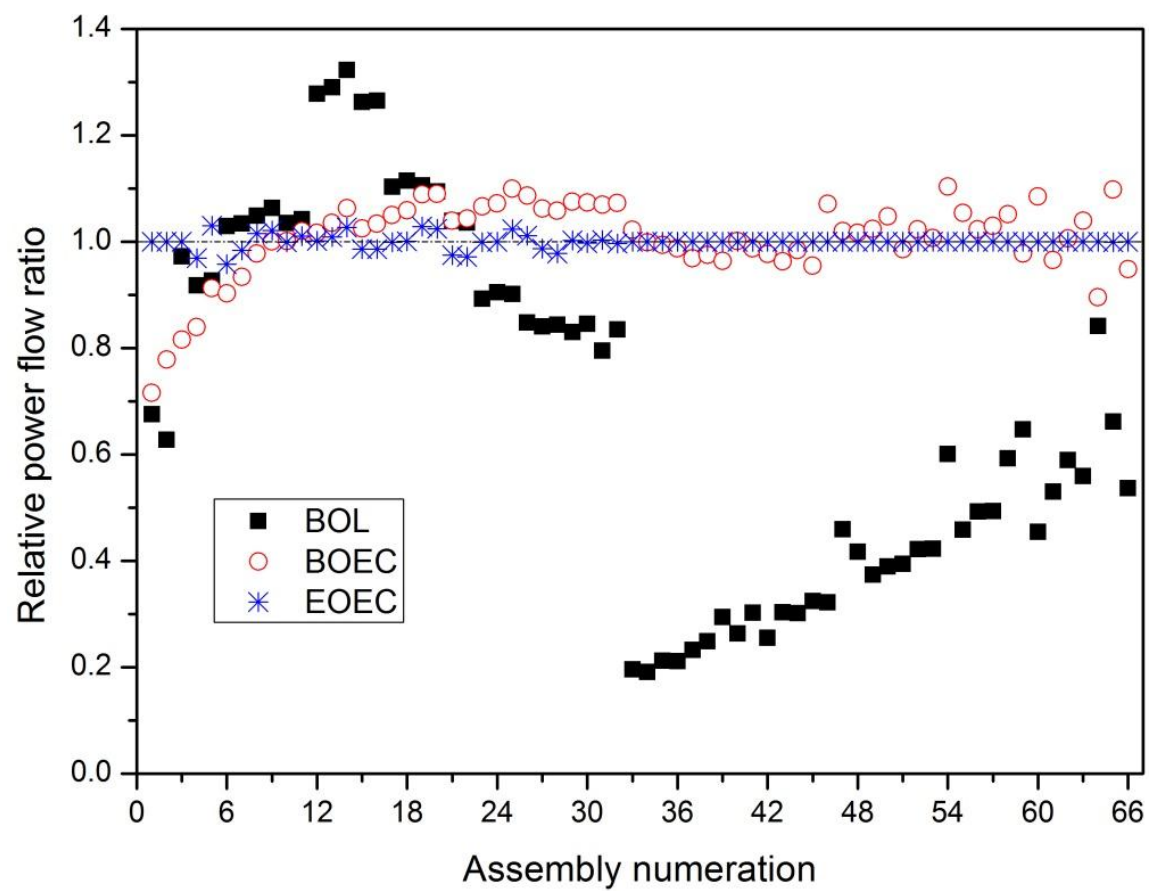

Fig. 23 Relative power flow ratio

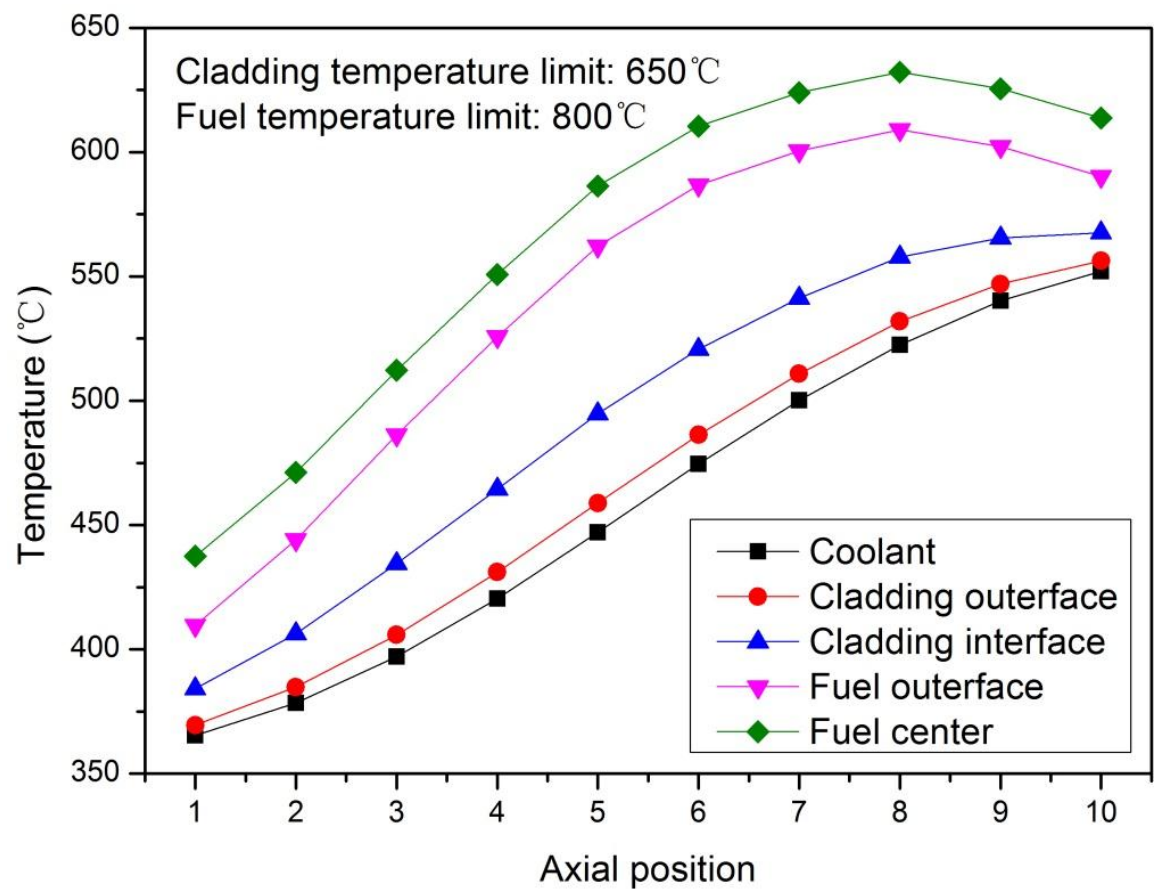

(a) BOL 


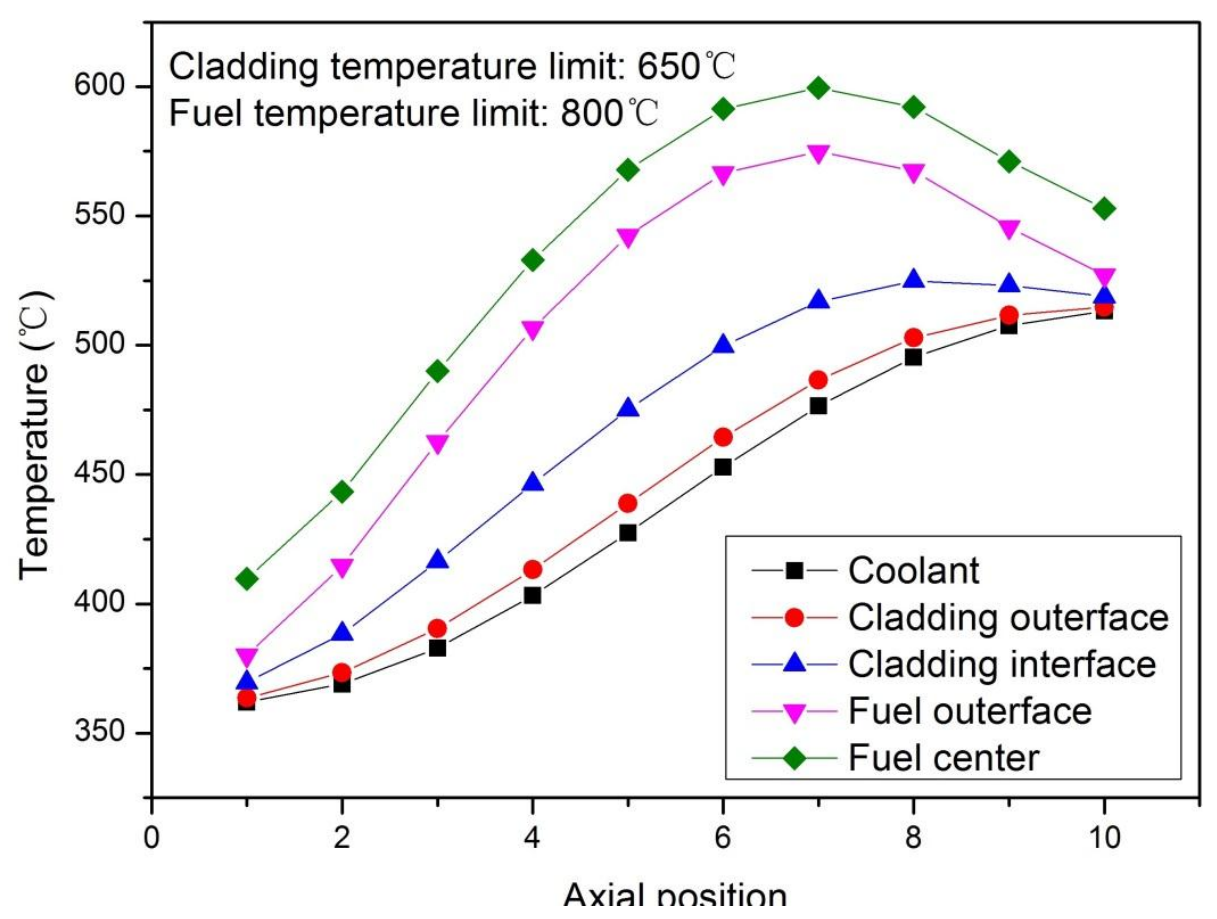

(b) BOEC

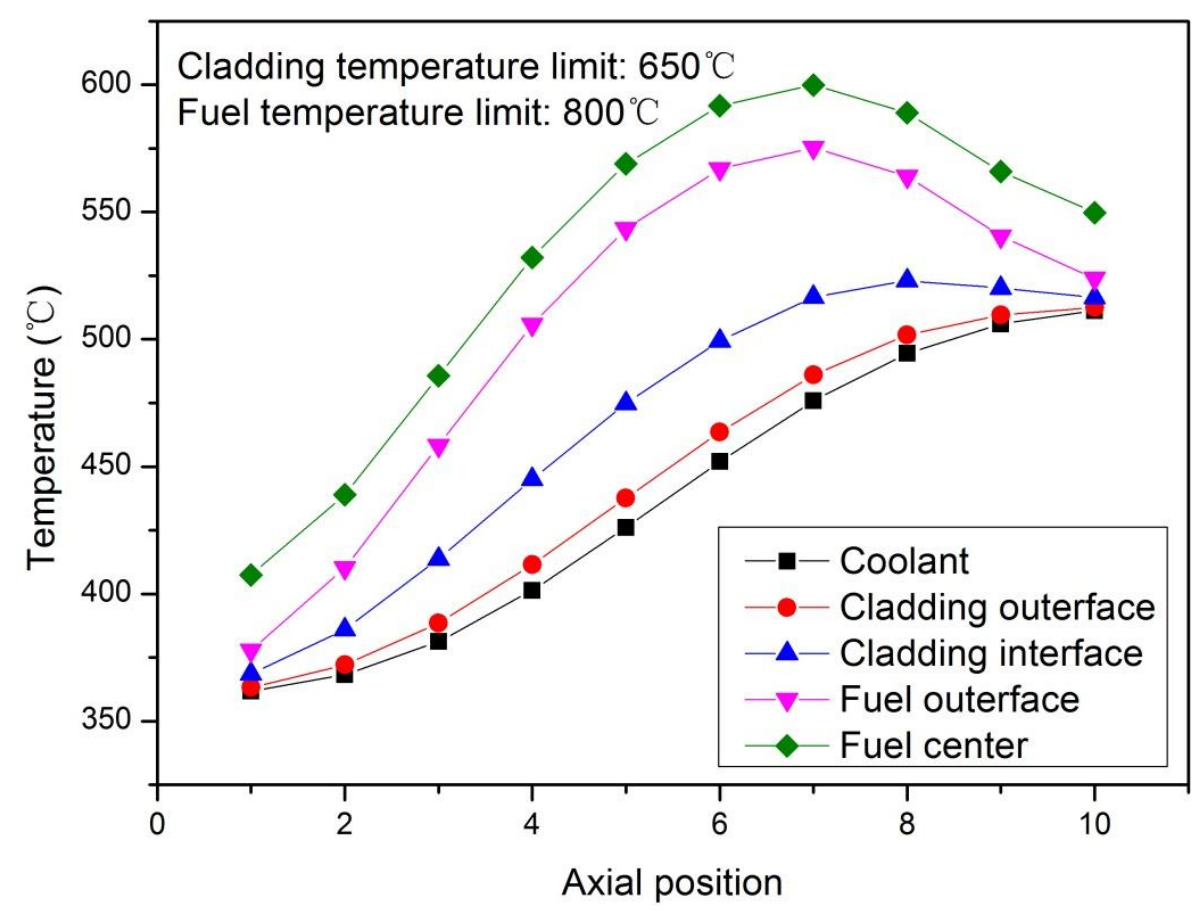

(c) EOEC

Fig. 24 Temperature distribution of hot channels for the optimized core design 


\section{Table list}

Table 1 Main parameters of assembly

Table 2 Detailed assembly parameters of 91 fuel rods with different P/D

Table 3 Detailed assembly parameters of 127 fuel rods with different P/D

Table 4 Detailed assembly parameters of 169 fuel rods with different P/D

Table 5 Detailed assembly parameters of 217 fuel rods with different P/D

Table 6 Detailed assembly parameters of 271 fuel rods with different P/D

Table 7 Detailed core parameters

Table 8 Main parameters of the best design core 


\section{Table 1}

Main parameters of assembly

\begin{tabular}{lc}
\hline Parameters & Value \\
\hline Inside flat-to-flat distance $(\mathrm{cm})$ & 15.86 \\
Outer flat-to-flat distance $(\mathrm{cm})$ & 16.46 \\
Assembly pitch $(\mathrm{cm})$ & 16.86 \\
Lower end plug $(\mathrm{cm})$ & 58.00 \\
Active core $(\mathrm{cm})$ & 250.00 \\
Upper plenum $(\mathrm{cm})$ & 200.00 \\
Upper end plug $(\mathrm{cm})$ & 2.50 \\
\hline
\end{tabular}


Table 2

Detailed assembly parameters of 91 fuel rods with different P/D

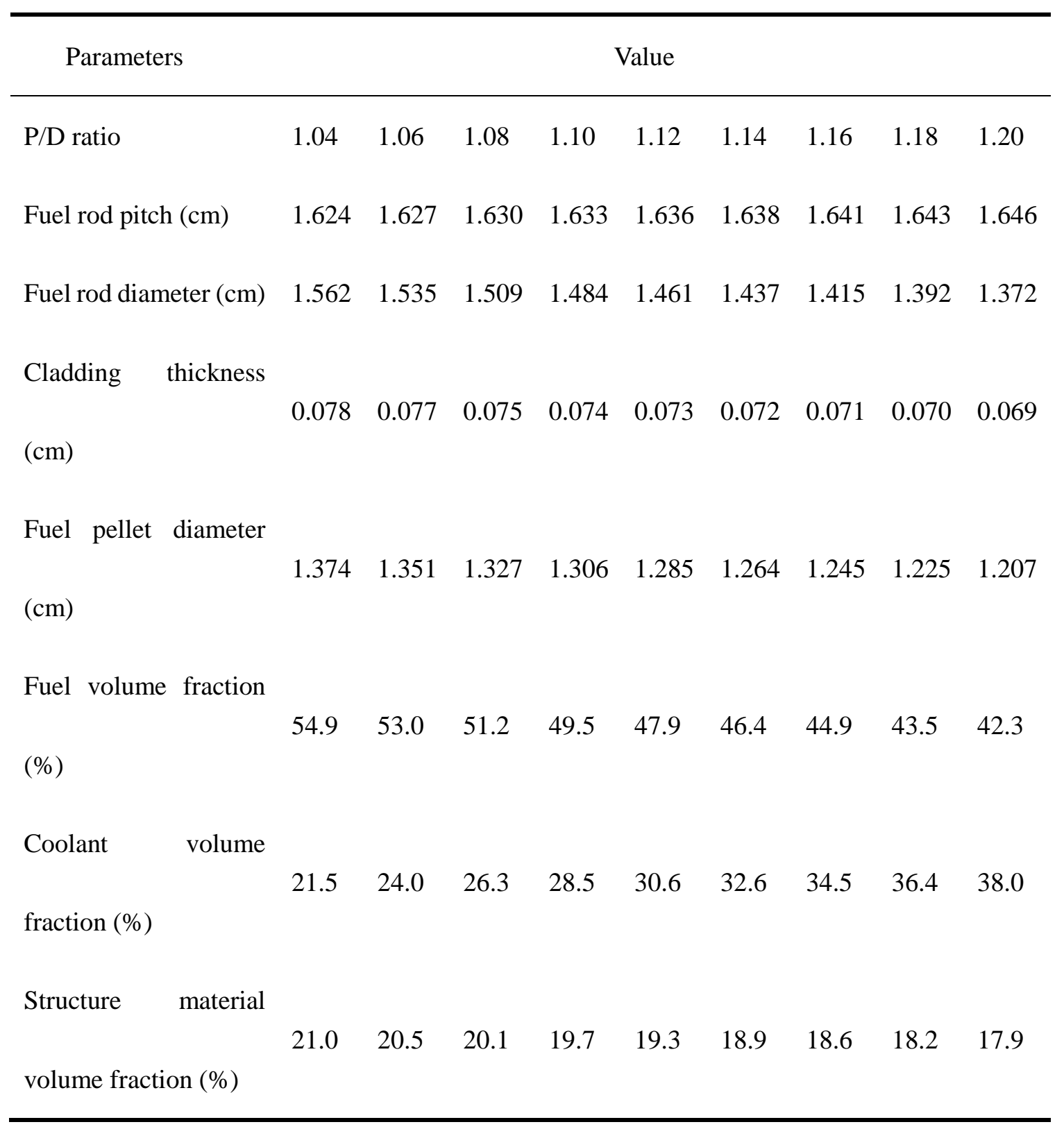


Table 3

Detailed assembly parameters of 127 fuel rods with different P/D

\begin{tabular}{|c|c|c|c|c|c|c|c|c|c|}
\hline Parameters & & & & & Value & & & & \\
\hline $\mathrm{P} / \mathrm{D}$ ratio & 1.04 & 1.06 & 1.08 & 1.10 & 1.12 & 1.14 & 1.16 & 1.18 & 1.20 \\
\hline Fuel rod pitch $(\mathrm{cm})$ & 1.376 & 1.378 & 1.380 & 1.382 & 1.384 & 1.386 & 1.388 & 1.390 & 1.392 \\
\hline Fuel rod diameter $(\mathrm{cm})$ & 1.323 & 1.300 & 1.278 & 1.256 & 1.236 & 1.216 & 1.196 & 1.178 & 1.160 \\
\hline $\begin{array}{l}\text { Cladding thickness } \\
(\mathrm{cm})\end{array}$ & 0.066 & 0.065 & 0.064 & 0.063 & 0.062 & 0.061 & 0.060 & 0.059 & 0.058 \\
\hline $\begin{array}{l}\text { Fuel pellet diameter } \\
(\mathrm{cm})\end{array}$ & 1.164 & 1.144 & 1.124 & 1.105 & 1.088 & 1.070 & 1.052 & 1.037 & 1.021 \\
\hline $\begin{array}{l}\text { Fuel volume fraction } \\
(\%)\end{array}$ & 54.9 & 53.0 & 51.2 & 49.5 & 47.9 & 46.4 & 44.9 & 43.5 & 42.3 \\
\hline $\begin{array}{l}\text { Coolant volume } \\
\text { fraction }(\%)\end{array}$ & 21.5 & 24.0 & 26.3 & 28.5 & 30.6 & 32.6 & 34.5 & 36.4 & 38.0 \\
\hline $\begin{array}{l}\text { Structure material } \\
\text { volume fraction }(\%)\end{array}$ & 21.0 & 20.5 & 20.1 & 19.7 & 19.3 & 18.9 & 18.6 & 18.2 & 17.9 \\
\hline
\end{tabular}


Table 4

Detailed assembly parameters of 169 fuel rods with different P/D

\begin{tabular}{|c|c|c|c|c|c|c|c|c|c|}
\hline Parameters & & & & & Value & & & & \\
\hline $\mathrm{P} / \mathrm{D}$ ratio & 1.04 & 1.06 & 1.08 & 1.10 & 1.12 & 1.14 & 1.16 & 1.18 & 1.20 \\
\hline Fuel rod pitch $(\mathrm{cm})$ & 1.194 & 1.196 & 1.198 & 1.199 & 1.200 & 1.202 & 1.203 & 1.204 & 1.206 \\
\hline Fuel rod diameter $(\mathrm{cm})$ & 1.148 & 1.128 & 1.109 & 1.090 & 1.071 & 1.054 & 1.037 & 1.022 & 1.005 \\
\hline $\begin{array}{l}\text { Cladding thickness } \\
(\mathrm{cm})\end{array}$ & 0.057 & 0.056 & 0.055 & 0.055 & 0.054 & 0.053 & 0.052 & 0.051 & 0.050 \\
\hline $\begin{array}{l}\text { Fuel pellet diameter } \\
(\mathrm{cm})\end{array}$ & 1.010 & 0.993 & 0.976 & 0.959 & 0.743 & 0.928 & 0.913 & 0.898 & 0.884 \\
\hline $\begin{array}{l}\text { Fuel volume fraction } \\
(\%)\end{array}$ & 54.9 & 53.0 & 51.2 & 49.5 & 47.9 & 46.4 & 44.9 & 43.5 & 42.3 \\
\hline $\begin{array}{l}\text { Coolant volume } \\
\text { fraction }(\%)\end{array}$ & 21.5 & 24.0 & 26.3 & 28.5 & 30.6 & 32.6 & 34.5 & 36.4 & 38.0 \\
\hline $\begin{array}{l}\text { Structure material } \\
\text { volume fraction }(\%)\end{array}$ & 21.0 & 20.5 & 20.1 & 19.7 & 19.3 & 18.9 & 18.6 & 18.2 & 17.9 \\
\hline
\end{tabular}


Table 5

Detailed assembly parameters of 217 fuel rods with different P/D

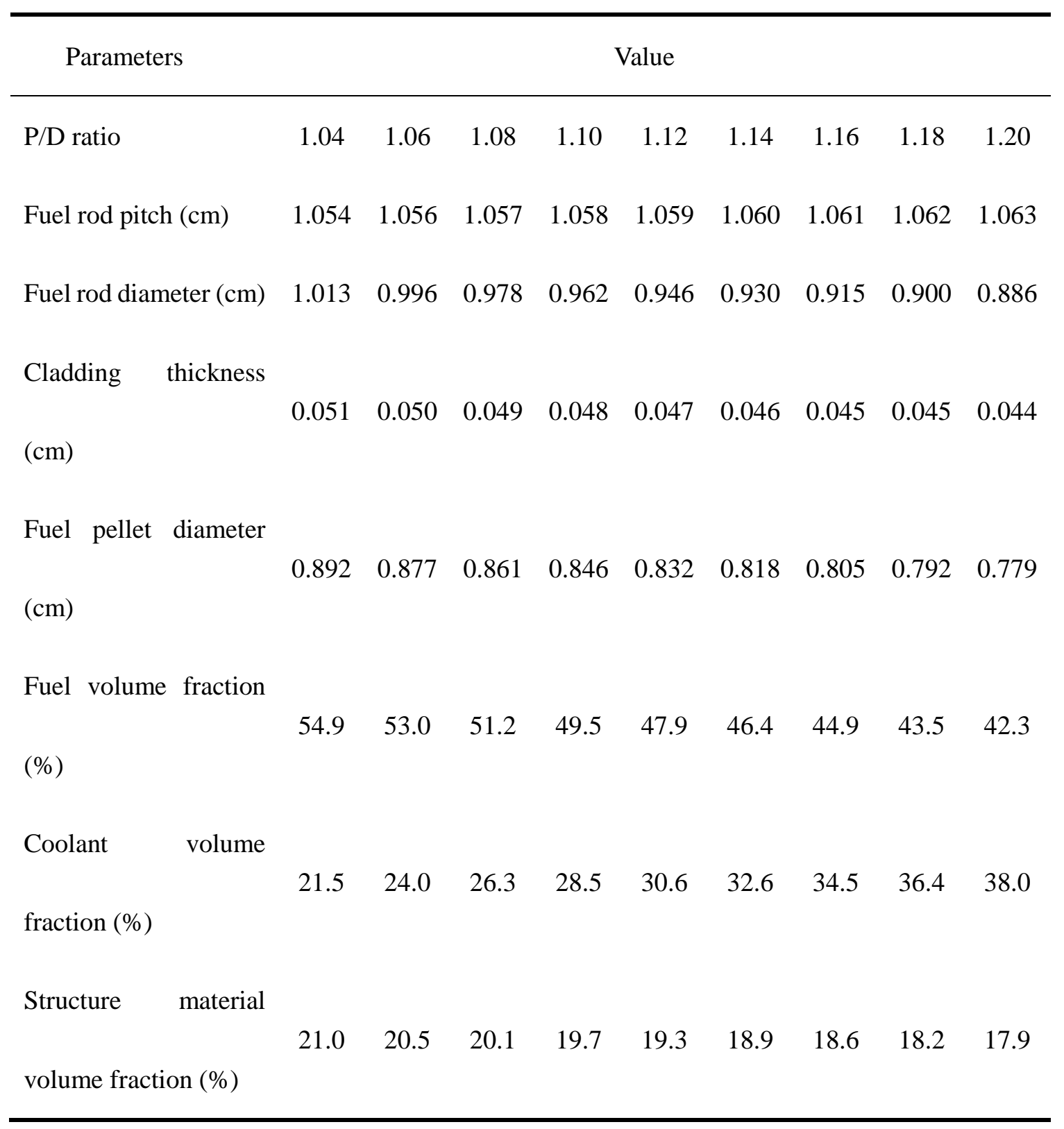


Table 6

Detailed assembly parameters of 271 fuel rods with different P/D

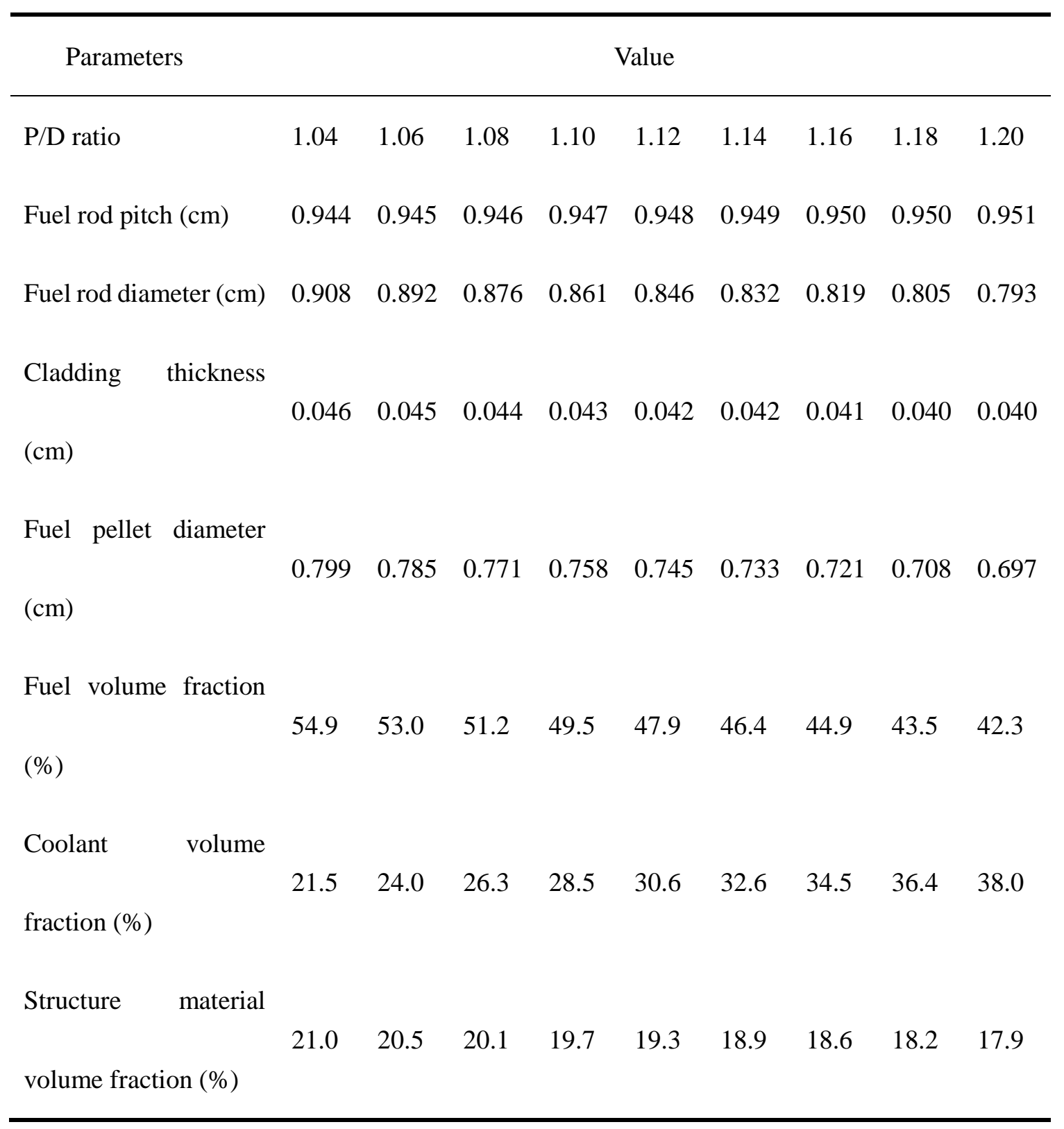


Table 7

Detailed core parameters

\begin{tabular}{|c|c|c|}
\hline Region & Height $(\mathrm{cm})$ & Material (Volume fraction \%) \\
\hline Lower shield & 20.0 & $47.9 \% \mathrm{~B}_{4} \mathrm{C}+19.3 \%$ HT9 $+30.6 \%$ Sodium \\
\hline Inlet cavity & 60.0 & $19.3 \%$ HT9 + $80.7 \%$ Sodium \\
\hline Grid plate & 5.0 & $50.0 \%$ HT9 $+50.0 \%$ Sodium \\
\hline Lower end plug & 58.0 & $19.3 \%$ HT9 + $80.7 \%$ Sodium \\
\hline Active core & 250.0 & $47.9 \%$ Fuel $+19.3 \%$ HT9 $+30.6 \%$ Sodium \\
\hline Upper plenum & 200.0 & $19.3 \%$ HT9 + $80.7 \%$ Sodium \\
\hline Upper end plug & 2.5 & $19.3 \%$ HT9 + $80.7 \%$ Sodium \\
\hline Upper reflector & 35.0 & $50.0 \%$ HT9 $+50.0 \%$ Sodium \\
\hline Inner duct & 250.0 & $19.3 \%$ HT9 + $80.7 \%$ Sodium \\
\hline Radial reflector & 508.0 & $50.0 \%$ HT9 $+50.0 \%$ Sodium \\
\hline Radial shield & 630.5 & $47.9 \% \mathrm{~B}_{4} \mathrm{C}+19.3 \%$ HT9 $+30.6 \%$ Sodium \\
\hline
\end{tabular}

*Equivalent thickness of each region can be obtained by the assembly pitch. 
Table 8

Main parameters of the best design core

\begin{tabular}{lccc}
\hline Parameters & BOL & BOEC & EOEC \\
\hline$k_{\text {eff }}$ & 1.03783 & 1.02742 & 1.04076 \\
Reactivity fluctuation (pcm) & & 5907.0 & \\
Average discharged burn-up (\%) & & 27.8 & \\
Radial power peaking factor & 2.98 & 2.81 & 2.86 \\
Doppler constant (pcm) & -112.6 & -75.7 & -66.4 \\
Void worth (pcm) & 1277.9 & 3422.9 & 3375.5 \\
Effective delayed neutron fraction & & & \\
$(\%)$ & 0.70 & 0.32 & 0.48 \\
\hline
\end{tabular}

